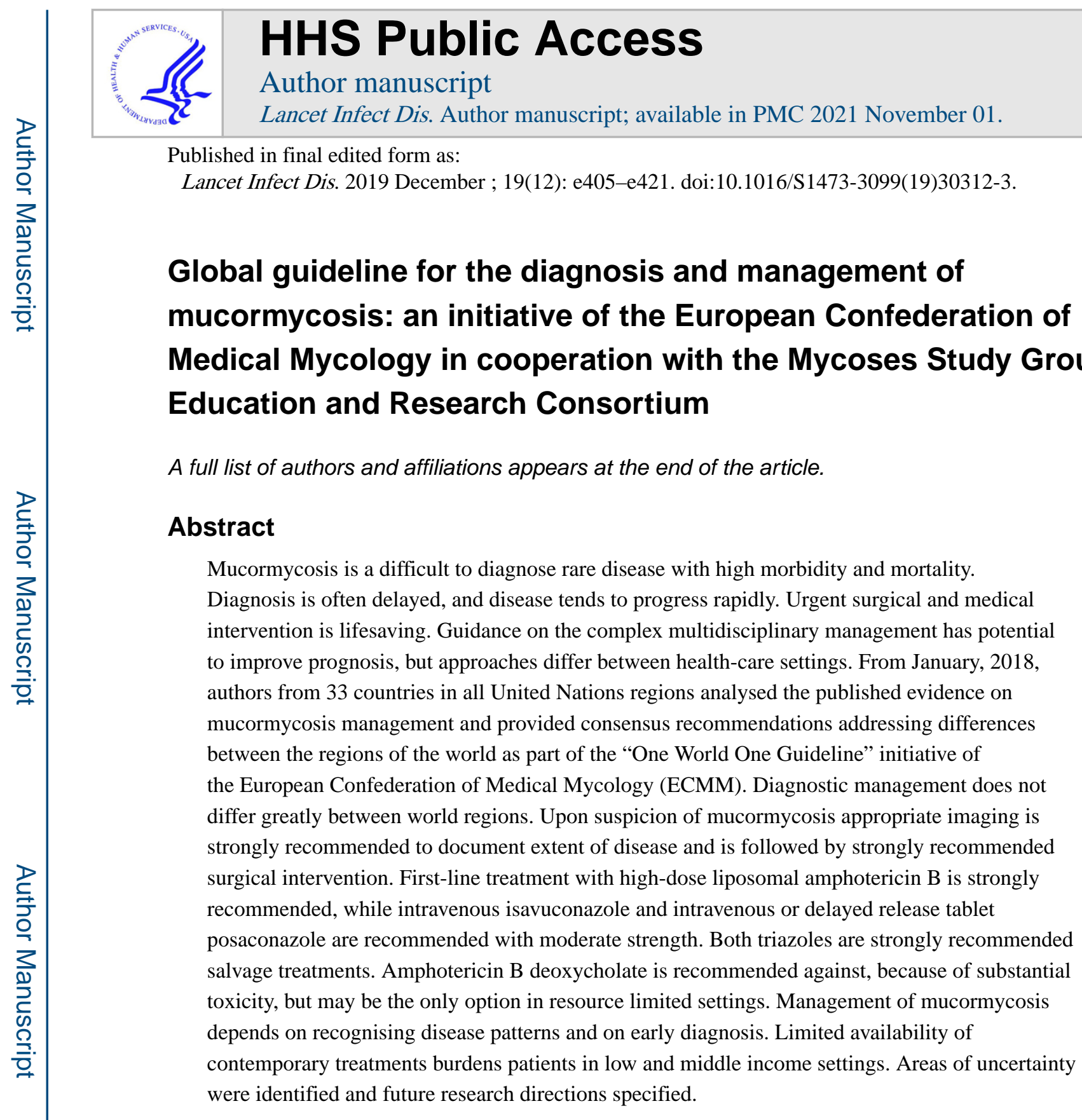

\title{
Introduction
}

Suspected mucormycosis requires urgent intervention, because of the often rapidly progressive and destructive nature of the infection. ${ }^{1,2}$ Delayed initiation of therapy is

\footnotetext{
Corrrespondence to: Oliver A Cornely MD, Department I of Internal Medicine, University Hospital Cologne, 50937 Cologne, Germany, oliver.cornely@uk-koeln.de.

Contributors

OAC and AC coordinated the work of the authors and guided the development of the guideline. OAC, AC, AAI, DA, SCAC, ED, BH, MH, HEJ, KL, REL, SCM, MMe, ZP, DS, DCS, and RW wrote the initial manuscript draft. All authors contributed to the literature review, compilation of data tables and interpretation and assessment of recommendations. All authors participated in review and revisions, approved the final manuscript, and are accountable for all aspects of the work in ensuring that questions related to the accuracy or integrity of any part of the work are appropriately investigated and resolved.

See Online for appendix

For the video tutorials see https://www.youtube.com/watch?v=ZrSd1_rSr0o
} 
associated with increased mortality. ${ }^{1}$ Maximising survival rates requires rapid diagnostic and therapeutic intervention, including immediate involvement of a multidisciplinary medical, surgical, radiological, and laboratory-based team. ${ }^{3}$ Readily available guidance is important to ensure efficient diagnosis and treatment, and to optimise patient prognosis. Optimal management depends on recognising disease patterns and the available diagnostic and therapeutic options, which differ between the regions of the world.

Currently available guidelines are limited to specific patient groups in haematology, ${ }^{4}$ or a specific geographical region, ${ }^{5}$ or require an update.${ }^{6-8}$ Recently, several critical developments have fundamentally changed the management of this condition. These include the development of new and more widely used molecular techniques for the diagnosis of mucormycosis, the licensing of isavuconazole for treatment of mucormycosis, and the availability of new formulations of posaconazole. Moreover, previous guidelines did not include comprehensive clinical and radiological imaging, pathological and histological findings, nor did they provide details on surgery as a core element of mucormycosis management.

The European Confederation of Medical Mycology (ECMM), together with the Mycoses Study Group Education \& Research Consortium (MSG ERC), issues this comprehensive guidance document to facilitate clinical decision-making, and simultaneously provides an overview of the areas of uncertainty in the field. ${ }^{9,10}$ We aimed to address limitations of previous recommendations, by engaging physicians and scientists involved in various aspects of mucormycosis management, representing the fields of microbiology, pathology, radiology, infectious diseases, surgery, paediatrics, haematology, intensive care, dermatology, and pharmcology. In addition, the guideline group comprises experts from all parts of the world and provides management pathways for different regional environments (panel; for further information on guideline development, systematic approach, authors and contributors, literature search terms and work flow, see appendix pp 1-4).

\section{Epidemiology of mucormycosis}

\section{Patient populations}

As medical science advances, the patient populations most at risk for mucormycosis expand accordingly. In the mid-20th century, diabetes evolved as a major risk factor for mucormycosis, while in more recent years, underlying malignancy emerged as another important risk factor due to the increasing number of patients undergoing chemotherapy or cancer immunotherapy. ${ }^{11-13}$ Furthermore, with more solid organ and haematopoietic stem-cell transplantations (HSCT) being performed, increasing numbers of cases have also been reported in these patient groups. ${ }^{14}$ At the same time, diabetes continues to represent the predominant risk factor for mucormycosis in settings where health-care access for diabetes management is more limited. ${ }^{13}$

For further information on patient populations, incidence and prevalence of mucormycosis and incidence rates compared to other mould infections, see appendix pp 4-6. 


\section{Pathogens causing mucormycosis}

The term mucormycosis is frequently used interchangeably with zygomycosis. The latter term referred to infections caused by fungi of the former phylum Zygomycota (comprising Mucorales, Entomophthorales, and others), which became obsolete with phylogenetic reanalysis of the kingdom Fungi. ${ }^{15,16}$ Today, mucormycosis describes infections caused by fungi of the order Mucorales. The most frequently reported pathogens in mucormycosis are Rhizopus spp, Mucor spp, and Lichtheimia spp (formerly of the genera Absidia and Mycocladus), followed by Rhizomucor spp, Cunninghamella spp, Apophysomyces spp, and Saksenaea spp. ${ }^{11,17,18}$ Lichtheimia spp were identified as the major cause of mucormycosis in a single hospital in Spain, indicating geographical variation and the need to know local epidemiology. ${ }^{19}$

\section{Clinical manifestations of mucormycosis}

For further information on clinical manifestations, see appendix $\mathrm{p} 6$.

In immunocompromised patients, the main route of infection seems to be through inhalation of sporangiospores causing pulmonary infection. Pulmonary mucormycosis typically develops in patients with profound neutropenia ${ }^{11}$ and graft-versus-host disease, ${ }^{20}$ whereas diabetic patients typically present with rhino-orbital disease. Prolonged fever is seen in most patients, although some patients might be asymptomatic. ${ }^{21}$ Radiological findings often vary in configuration, size, number, and distribution of lesions; typical examples are given below. ${ }^{22-25}$ Pulmonary mucormycosis can spread contiguously into other organs, for example through the diaphragm into the abdomen.

Cutaneous and soft-tissue mucormycosis are the most common forms of mucormycosis in immunocompetent patients, primarily after skin disruption due to traumatic injury (eg from natural disasters, motor vehicle accidents, improvised explosive devices in theatres of war, or iatrogenic sources), surgery, or burns. ${ }^{26-31}$ Abscesses, skin swelling, necrosis, dry ulcers, and eschars are characteristic presentations (figure $1 \mathrm{~A}$ and $\mathrm{G}$ ). ${ }^{32-34}$

For further information on cutaneous and soft-tissue mucormycosis, see appendix p 6.

Rhino-orbito-cerebral mucormycosis typically develops in patients with diabetes, whereas such patients very rarely develop lung infection. ${ }^{11}$ It has been described in haematology patients, too. ${ }^{35}$ Rhino-orbital-cerebral infection usually originates from the paranasal sinuses, with bone destruction and subsequent invasion of the orbit, eye, and brain. ${ }^{36-39}$ Unilateral facial oedema, proptosis, and palatal or palpebral fistula developing into necrosis may be present (figure 1B, F).

For further information on rhino-orbito-cerebral mucormycosis see appendix $\mathrm{p} 6$.

Primary gastrointestinal disease is a rare manifestation of mucormycosis that can present with symptoms similar to other common gastrointestinal diseases. ${ }^{40,41}$ However, gastrointestinal mucormycosis is the most common manifestation of mucormycosis in neonates, where it carries a high mortality. ${ }^{42}$

For further information on gastrointestinal mucormycosis, see appendix $\mathrm{p} 6$. 
Cases of isolated renal mucormycosis in immunocompetent hosts are extremely rare, but have been reported from China and India. ${ }^{43-48}$

For further information on renal and abdominal mucormycosis, see appendix $\mathrm{p} 7$.

\section{Mortality}

All-cause mortality rates for mucormycosis range from $40 \%$ to $80 \%$ with varying rates depending on underlying conditions and sites of infection. ${ }^{11,19,49-51}$ The highest survival rates are reported in patients with a healthy immune status and those without comorbidities. The poorest prognosis is observed in patients with haematological malignancies and HSCT recipients ${ }^{11}$ and in patients with extensive burns. ${ }^{51}$ Disseminated disease, especially to the CNS is often associated with mortality rates higher than $80 \% .{ }^{11}$ Conversely, lower mortality is seen with localised sinus or skin infection, where earlier tissue-based diagnosis is often feasible and surgical debridement may result in cure. Mortality is also high in neonates and other immunocompromised patients with gastrointestinal mucormycosis, possibly related to delay in diagnosis and polymicrobial sepsis. Generally, improved survival is related to earlier diagnosis and application of early, multidisciplinary treatment approaches involving aggressive surgical debridement. ${ }^{19,52-54}$ Despite improved understanding of the disease and the availability of more therapeutic options, survival rates in mucormycosis remain poor. ${ }^{19,55,56}$

\section{Diagnosis}

The capability of diagnosing mucormycosis depends on the availability of imaging techniques, trained personnel, and mycological and histological investigations. Patients with suspected mucormycosis should be referred immediately to a facility with the highest care level. In case of any delay, management should be initiated following this guidance document. If all diagnostic options are available, one should follow the management pathway depicted in figure 2 .

For further information on diagnosing mucormycosis, see appendix $\mathrm{p} 7$.

\section{Imaging}

Radiographical signs suggestive of pulmonary mucormycosis are shown in figure 3. For further information on imaging see appendix $\mathrm{p} 7$.

Recommendations-In patients with haematological malignancy and suspected pulmonary mucormycosis, pulmonary $\mathrm{CT}$ scan is recommended for the detection of the reversed halo sign, an area of ground glass opacity surrounded by a ring of consolidation on thoracic $\mathrm{CT}$, or vessel occlusion on CT pulmonary angiography. In diabetic patients with facial pain, sinusitis, proptosis, ophthalmoplegia, or newly diagnosed amaurosis, or both, cranial CT or MRI is strongly recommended to determine if sinusitis is present. If sinusitis is diagnosed, endoscopy is strongly recommended to diagnose mucormycosis. If disease of the eye or brain is suspected, MRI should be conducted in lieu of a CT scan due to substantially greater sensitivity. If mucormycosis is a potential diagnosis, biopsy is strongly recommended. Once mucormycosis has been proven in a patient with 
underlying malignancy, cranial, thoracic and abdominal imaging studies to determine the extent of disease are recommended with moderate strength. In view of the rapid progress of mucormycosis, weekly CT scans are strongly recommended, particularly in unstable patients (appendix p 7).

\section{Histopathology in mucormycosis}

Evidence-Mucormycosis is usually suspected based on results of direct microscopy of clinical specimens, preferably stained with fluorescent brighteners calcofluor white (Sigma Aldrich, St Louis, MO, USA) or blankophor (Tanatax Chemicals, Ede, The Netherlands). To confirm an infection, non-pigmented hyphae showing tissue invasion must be shown in tissue sections stained with haematoxylin-eosin (HE), periodic acid-Schiff stain (PAS), or Grocott-Gomori's methenamine-silver stain (GMS), or both. ${ }^{57,58}$ Histopathologically, Mucorales hyphae have a variable width of $6-16 \mu \mathrm{m}$, but may be up to $25 \mu \mathrm{m}$, and are nonseptate or pauci-septate. In tissue, the hyphae appear ribbon-like with an irregular pattern of branching (figure 4A-C) ${ }^{57}$ Hyphae can artefactually seem to have septae because tissue can fold over itself during processing, which can create artificial lines that can be confused with septations. Similarly, the historically described $90^{\circ}$ branching angle of Mucorales in tissue, versus $45^{\circ}$ branching angle of septate moulds, can be difficult to identify in tissue due to interstitial pressures exerted on the fungi by the tissue and alterations in tissue architecture during processing. Thus the wider and irregular (ribbon-like) nature of the hyphae are more reliable distinguishing characteristics than septations and angle of branching.

The lesions of mucormycosis are characteristic but nonspecific. ${ }^{59-61}$ In acute lesions, haemorrhagic infarction, coagulation necrosis, angioinvasion, infiltration by neutrophils (in non-neutropenic hosts), and perineural invasion are characteristic features; ${ }^{62}$ whereas, in chronic lesions, a pyogranulomatous inflammation with presence of giant cells, and sometimes hyphae covered by the Splendore-Hoeppli phenomenon, ${ }^{63,64}$ which describes deeply eosinophilic material surrounding the pathogen, are seen (figure A-C). ${ }^{17,62,65-67}$

Obtaining a diagnosis of mucormycosis on histomorphological basis is challenging, and the most common cause for incorrect morphological diagnosis is the misidentification of Mucorales as Aspergillus spp (figure A-C) ${ }^{58}$ The application of immunohistochemistry with commercially available monoclonal antibodies ${ }^{68-70}$ or PCR techniques on either fresh or formalin-fixed paraffin-embedded tissue ${ }^{19,71-95}$ have been shown to be highly specific, although a variation in sensitivity has been reported, in addition, these tests might not be widely available (appendix p 9).

Recommendations-Hyphae of Mucorales can be distinguished from septate hyaline moulds due to their greater width and irregular pattern of branching. However, there are no data available to describe the accuracy of distinguishing Mucorales from other moulds based on these characteristics. Therefore, it is strongly recommended to confirm the diagnosis of mucormycosis in tissue by culture or by application of molecular or in-situ identification techniques, at centres where such assays are available (appendix p 9).

For further information on antigen biomarkers, see appendix p 10. 


\section{Culture and microscopy}

Recommendations-Culture of specimens is strongly recommended for genus and species identification, and for antifungal susceptibility testing. Homogenisation of tissue should be avoided before culturing. Incubation at $30^{\circ} \mathrm{C}$ and $37^{\circ} \mathrm{C}$ separately is strongly recommended (appendix p 11). Direct microscopy with fluorescent brighteners from clinical specimens is strongly recommended mainly focusing on septation, branching angle, and hyphal width.

For further information on culture and microscopy, see appendix $\mathrm{p} 10$.

\section{Susceptibility testing}

For further information on susceptibility testing, see appendix p 11-12.

Recommendations-The use of standard methods for antifungal susceptibility testing to guide antifungal treatment in Mucorales is marginally supported and may be clinically useful in cases of treatment failure. However, we strongly recommend the use of these methods primarily to establish epidemiological knowledge in the field. Currently, commercial methods such as E-test are recommended for use in mucormycosis with marginal strength only (appendix p 11).

\section{Molecular-based methods for direct detection}

For further information on molecular-based methods, see appendix $\mathrm{p} 13$.

Currently, in the absence of a standardised test, the use of molecular methods on both fresh clinical material and paraffin sections for the diagnosis of mucormycosis is moderately supported. Fresh material is preferred over paraffin-embedded tissue because formalin damages DNA. Detection of DNA in serum as well as in other body fluids is very promising but because of lack of standardisation supported with moderate strength only (appendix $p$ $13)$.

\section{Genus and species identification}

Evidence-Although some genera, such as Cunninghamella, can be associated with an increased mortality rate in patients ${ }^{11,96}$ and have been shown to be more virulent in experimental models, ${ }^{97}$ there is currently sparse evidence that identification of the causative Mucorales to the genus or species level, or both, could guide the choice of the antifungal treatment.

By contrast, identification to the species level is of importance for improved epidemiological knowledge of the disease. In particular, the clinical picture can be different depending on the species. ${ }^{11,96,98,99}$ Moreover, species identification is valuable for investigation of health care-associated mucormycosis and outbreaks. ${ }^{100-103}$

For further information on genus and species identification, see appendix p 14-15.

Recommendations-Identification to the genus and species level is strongly supported for improved epidemiological understanding of mucormycosis. Guiding treatment by 
identification to the genus level is supported with marginal strength. Molecular identification is strongly supported and preferred over morphology. Because the best technique for molecular identification, internal transcribed spacer (ITS) sequencing is strongly supported. Matrix assisted laser desorption ionisation time of flight (MALDI-TOF) identification is moderately supported because it relies mainly on in-house databases, and many laboratories do not have that capacity (appendix p 15).

\section{Treatment approaches to mucormycosis}

The ability to treat mucormycosis effectively depends on the availability of the surgical techniques and antifungal drugs discussed below. If all treatment options are available one should follow the management pathways detailed in figure 5A and appendix $\mathrm{p} 25$. If local or regional capabilities differ, less comprehensive pathways need to be followed; examples are given in figure 5B, C, and appendix p 26.

Surgical treatment for mucormycosis-For further information on surgical treatment, see appendix p 16.

Recommendations - The guideline group strongly supports an early complete surgical treatment for mucormycosis whenever possible, in addition to systemic antifungal treatment. Resection or debridement should be repeated as required (appendix p 16).

\section{Drug treatment for mucormycosis}

Prophylaxis-For further information on prophylaxis, see appendix p 18.

Recommendations - In neutropenic patients or those with graft versus host disease, primary prophylaxis with posaconazole delayed release tablets is recommended with moderate strength, and prophylaxis with oral suspension is recommended with marginal strength to prevent mucormycosis.

Secondary prophylaxis-For further information on secondary prophylaxis, see appendix p 18.

Recommendations - In immunosuppressed patients with previous diagnosis of mucormycosis, surgical resection and continuation or restart of the last drug effective in that patient is strongly recommended.

Fever-driven treatment-For further information on fever-driven treatment, see appendix p 19.

Recommendations - The guideline group recommends against initiation of treatment for mucormycosis when fever of unknown origin is the sole evidence of infection.

Diagnosis-driven treatment-For further information on fever-driven treatment, see appendix p 19. 
Recommendations - In any immunocompromised patient with suspected mucormycosis, immediate treatment initiation is strongly ecommended. Every attempt to attain a diagnosis should be made at the time of initiation of therapy, but should not delay therapy.

First-line antifungal monotherapy—Evidence-In several case series, the use of liposomal amphotericin B successfully treated mucormycosis with various organ involvement patterns. ${ }^{17,50,67,104-109}$ Daily doses ranged from $1 \mathrm{mg} / \mathrm{kg}$ per day to 10 $\mathrm{mg} / \mathrm{kg}$ per day. ${ }^{104,110}$ Recipients of increased doses tended to have increased response rates. ${ }^{104}$ Patients receiving $10 \mathrm{mg} / \mathrm{kg}$ per day had substantial serum creatinine increases that were mostly reversible. ${ }^{104,106}$ Doses higher than $10 \mathrm{mg} / \mathrm{kg}$ per day did not result in higher blood concentrations. ${ }^{111}$ In CNS involvement, animal models and the above observations support use of liposomal amphotericin B at $10 \mathrm{mg} / \mathrm{kg}$ per day. ${ }^{112} \mathrm{In}$ the absence of CNS involvement, amphotericin B lipid complex $5 \mathrm{mg} / \mathrm{kg}$ per day has been used successfully. ${ }^{17,112,113}$ In kidney transplant recipients, amphotericin B lipid complex $10 \mathrm{mg} / \mathrm{kg}$ per day has been given. ${ }^{114}$ Amphotericin B deoxycholate has been the drug of choice for decades. ${ }^{11,17,66,109}$ It is effective, but its use is limited by its substantial toxicity, specifically in the doses and treatment durations needed for mucormycosis (table 2). ${ }^{115,116}$ Use of amphotericin B deoxycholate should be restricted to settings in which there is no other antifungal therapy available.

The efficacy of isavuconazole was similar to an external matched control group treated with amphotericin B formulations. This limited size study enrolled 21 patients with isavuconazole first-line treatment, and compared efficacy results to 33 matched patients from the FungiScope registry. ${ }^{49,117}$ As a result, isavuconazole has been licenced in the USA for first-line treatment of mucormycosis. ${ }^{118}$ By contrast with other mould-active azoles, isavuconazole is less hepatotoxic although it can result in shortening the QTc interval. ${ }^{19-121}$ Posaconazole oral suspension has been used successfully in first-line treatment. ${ }^{17,67}$ Recently, concerns about its oral bioavailability led to the development of a delayed release tablet with improved exposure ${ }^{122,123}$ and an intravenous infusion formulation (table 2). ${ }^{124,125}$

Recommendations - First-line treatment with liposomal amphotericin B 5-10 mg/kg per day is strongly supported across all patterns of organ involvement. If substantial renal toxicity develops, the dose can be reduced as necessary, but doses below $5 \mathrm{mg} / \mathrm{kg}$ per day are recommended with marginal strength only. ${ }^{104,110}$ Doses should not be slowly increased over several days; rather, the full daily dose should be given from the first treatment day. Amphotericin B lipid complex $5 \mathrm{mg} / \mathrm{kg}$ per day is recommended with moderate strength for patients without CNS involvement. Use of amphotericin B deoxycholate is discouraged whenever alternatives are available. Isavuconazole is recommended with moderate strength for the first-line treatment of mucormycosis. The group marginally supports use of posaconazole oral suspension, and moderately supports posaconazole delayed release tablets and infusion for first-line treatment (table 2).

First-line antifungal combination therapy—Evidence—-In animal models, some antifungal combinations have shown the potential to improve cure and survival rates with no antagonism noted. ${ }^{126,127}$ Results from some patient series are promising. ${ }^{128-130}$ However, 
a historical control study ${ }^{55}$ and a propensity score analysis failed to show benefits of double and triple antifungal combinations in patients with haematological malignancy. ${ }^{108}$ In trauma patients, specifically in blast injury, more than one mould species can cause mixed infection warranting empirical combination therapy with liposomal amphotericin B and either posaconazole or voriconazole. ${ }^{29,131}$ The downsides of combination therapy are unclear aside from potential added toxicity, drug interactions, and cost.

Recommendations - There are no definitive data to guide the use of antifungal combination therapy. Limited data support combinations of polyenes and azoles or polyenes plus echinocandins. Combination therapy can be rationally given due to lack of enhanced toxicity with possible but unproven benefit; however, data are too limited to support this beyond a marginal recommendation.

For further information on first-line combination therapy, see appendix p 19.

Antifungal salvage treatment-Evidence-In general, there are two drug-related reasons for treatment failures, refractory mucormycosis or toxicity of first-line regimens -ie, intolerance to a drug. For amphotericin B formulations, particularly renal toxicity can be a limiting factor, while for the azole class hepatic toxicity has the highest prevalence. Toxicity can be caused by previous antifungals, or expected due to preexisting organ damage. Only two drug classes have proven efficacy in mucormycosis, thus salvage treatment mostly means switching to the other class. Isavuconazole salvage treatment was successful in both clinical scenarios, refractory disease, and intolerance or toxicity. ${ }^{49,132}$ In Europe, isavuconazole is licenced for salvage treatment of mucormycosis only. Posaconazole treatment with oral suspension achieved cure in two non-randomised clinical trials ${ }^{133,134}$ and in case series. ${ }^{17,135}$ Liposomal amphotericin B was effective as salvage treatment, ${ }^{109}$ as was amphotericin B lipid complex, ${ }^{113,136}$ and amphotericin B colloidal dispersion. ${ }^{137}$

Recommendations-Isavuconazole is strongly supported as salvage treatment. Posaconazole delayed release tablets or infusions are strongly supported for salvage treatment, and when available should be preferred over posaconazole oral suspension, which in turn is marginally supported for salvage treatment. In cases of primary treatment failure with isavuconazole or posaconazole, the guideline group supports recommendations for all three lipid-based amphotericin B formulations with strong to moderate strength.

For further information on salvage treatment, see appendix $\mathrm{p} 20$.

Treatment duration for mucormycosis-Evidence-The duration of therapy necessary to treat mucormycosis is unknown. In general, weeks to months of therapy are given. If immune defect is resolved —eg diabetes is controlled, neutropenia definitively resolved, immunosuppression can be tapered or stopped, therapy can be continued until resolution of signs and symptoms of infection, and substantial radiographical improvement. Median duration of isavuconazole first-line or salvage treatment was 84 days intravenous or oral route or both. ${ }^{49}$ Across several posaconazole oral suspension studies, treatment duration ranged from 1 week to almost 3 years, mean duration was approximately 6 
months. ${ }^{113,133,134,138,139}$ The wide range reflects the pattern of organs involved, with competing risks from underlying conditions. Late relapse in long-term survivors have been documented (appendix p 21). ${ }^{140}$

Recommendations - The guideline group strongly supports treatment until permanent reversal of immunosuppression and complete response on imaging, which might be difficult to determine because of scarring and postoperative changes. Treatment duration is a personalised decision. There is moderate support for intravenous treatment until stable disease is achieved. When switching to oral treatment, use of isavuconazole or posaconazole delayed release tablets is strongly supported. Posaconazole oral suspension can be used, but is marginally supported, especially when formulations with higher exposure are available (appendix p 21).

Therapeutic drug monitoring in mucormycosis (appendix p 22), specific considerations on treatment of mucormycosis in children (appendix p 23), adjunctive treatments for mucormycosis (appendix p 27), intensive care and crtically ill patients with mucormycosis (appendix p 29), health economics (appendix p 29), and future directions (appendix p 30) are available in the appendix where indicated.

Treatment pathways for mucormycosis-The proposed treatment algorithms for adult (appendix p 25; figure 5) and for paediatric patients (appendix p 25) are based on case series, retrospective studies, and expert opinion. Large, randomised controlled trials investigating efficacy of treatment regimens are lacking. Surgical debridement should be performed whenever feasible in parallel to antifungal treatment. ${ }^{11,17,141,142}$ The drug of choice is liposomal amphotericin B. ${ }^{67,109}$ In case of renal failure, posaconazole or isavuconazole were shown to be effective. If a patient is intolerant to liposomal amphotericin B, its dose can be reduced, but should stay $25 \mathrm{mg} / \mathrm{kg}$ bodyweight. In case of extensive disease, rapid progression, or poor general condition, the addition of isavuconazole or posaconazole can be considered. ${ }^{133-135}$

Treatment should be continued until resolution of initially indicative findings on imaging and reconstitution of host immune system. Isavuconazole or posaconazole may be administered as maintenance therapy. ${ }^{143}$

\section{Supplementary Material}

Refer to Web version on PubMed Central for supplementary material.

\section{Authors}

Oliver A Cornely, Ana Alastruey-Izquierdo, Dorothee Arenz, Sharon C A Chen, Eric Dannaoui, Bruno Hochhegger, Martin Hoenigl, Henrik E Jensen, Katrien Lagrou, Russell E Lewis, Sibylle C Mellinghoff, Mervyn Mer, Zoi D Pana, Danila Seidel, Donald C Sheppard, Roger Wahba, Murat Akova, Alexandre Alanio, Abdullah M S Al-Hatmi, Sevtap Arikan-Akdagli, Hamid Badali, Ronen Ben-Ami, Alexandro Bonifaz, Stéphane Bretagne, Elio Castagnola, Methee Chayakulkeeree, Arnaldo L Colombo, Dora E Corzo-León, Lubos Drgona, Andreas H Groll, Jesus Guinea, 
Claus-Peter Heussel, Ashraf S Ibrahim, Souha S Kanj, Nikolay Klimko, Michaela Lackner, Frederic Lamoth, Fanny Lanternier, Cornelia Lass-Floerl, Dong-Gun Lee, Thomas Lehrnbecher, Badre E Lmimouni, Mihai Mares, Georg Maschmeyer, Jacques F Meis, Joseph Meletiadis, C Orla Morrissey, Marcio Nucci, Rita Oladele, Livio Pagano, Alessandro Pasqualotto, Atul Patel, Zdenek Racil, Malcolm Richardson, Emmanuel Roilides, Markus Ruhnke, Seyedmojtaba Seyedmousavi, Neeraj Sidharthan, Nina Singh, János Sinko, Anna Skiada, Monica Slavin, Rajeev Soman, Brad Spellberg, William Steinbach, Ban Hock Tan, Andrew J Ullmann, Jörg J Vehreschild, Maria J G T Vehreschild, Thomas J Walsh, P Lewis White, Nathan P Wiederhold, Theoklis Zaoutis, Arunaloke Chakrabarti, Mucormycosis ECMM MSG Global Guideline Writing Group

\section{Affiliations}

(O A Cornely MD, D Arenz PhD, J J Vehreschild MD, M J G T Vehreschild MD, S C Mellinghoff MD, D Seidel PhD); German Centre for Infection Research (DZIF) partner site Bonn-Cologne, Cologne, Germany (O A Cornely, J J Vehreschild, M J G T Vehreschild); CECAD Cluster of Excellence, University of Cologne, Cologne, Germany (O A Cornely, D Arenz, S C Mellinghoff, D Seidel); Clinical Trials Center Cologne, University Hospital of Cologne, Cologne, Germany (O A Cornely); Mycology Reference Laboratory, National Centre for Microbiology, Instituto de Salud Carlos III, Madrid, Spain (A Alastruey-Izquierdo PhD); Centre for Infectious Diseases and Microbiology Laboratory Services, New South Wales Health Pathology, and the Department of Infectious Diseases, Westmead Hospital, School of Medicine, University of Sydney, Sydney, NSW, Australia (S C-A Chen PhD); Université ParisDescartes, Faculté de Médecine, APHP, Hôpital Européen Georges Pompidou, Unité de Parasitologie-Mycologie, Service de Microbiologie, Paris, France (E Dannaoui MD); Radiology, Hospital São Lucas da Pontificia Universidade Catolica do Rio Grande do Sul (PUCRS), Escola de Medicina, Porto Alegre, Brazil (B Hochhegger MD); Radiology, Universidade Federal de Ciências da Saúde de Porto Alegre (UFCSPA), Porto Alegre, Brazil (B Hochhegger); Section of Infectious Diseases and Tropical Medicine and Division of Pulmonology, Medical University of Graz, Graz, Austria (M Hoenigl MD); Division of Infectious Diseases and Global Public Health, Department of Medicine, University of California San Diego, San Diego, USA (M Hoenigl); Faculty of Health and Medical Sciences, University of Copenhagen, Copenhagen, Denmark (H E Jensen PhD); Department of Microbiology, Immunology and Transplantation, KU Leuven and Clinical Department of Laboratory Medicine and National Reference Center for Mycosis, University Hospitals Leuven, Leuven, Belgium (K Lagrou PharmD); Infectious Diseases Clinic, Sant'Orsola-Malpighi Hospital, Department of Medical and Surgical Sciences, University of Bologna, Bologna, Italy (R E Lewis PharmD); Divisions of Critical Care and Pulmonology, Department of Medicine, Charlotte Maxeke Johannesburg Academic Hospital and Faculty of Health Sciences University of the Witwatersrand, Johannesburg, South Africa 
(M Mer MD); Infectious Diseases Unit, 3rd Department of Paediatrics, Faculty of Medicine, Aristotle University School of Health Sciences, Thessaloniki, Greece; Hippokration General Hospital, Thessaloniki, Greece (Z D Pana MD; E Roilides MD); Division of Infectious Diseases, Department of Medicine, Microbiology and Immunology, McGill University, Montreal, Quebec, Canada (D C Sheppard MD); Department of General, Visceral and Cancer Surgery, University Hospital of Cologne, Cologne, Germany (R Wahba MD); Department of Medical Microbiology, Postgraduate Institute of Medical Education \& Research, Chandigarh, India (A Chakrabarti MD); Department of Infectious Diseases, Hacettepe University School of Medicine, Ankara, Turkey (M Akova MD); Institut Pasteur, National Reference Center for Invasive Mycoses and Antifungals, Department of Mycology, CNRS UMR2000, ParasitologyMycology Laboratory, Lariboisière, Saint-Louis, Fernand Widal Hospitals, Assistance Publique-Hôpitaux de Paris (AP-HP), Université de Paris, Paris, France (A Alanio MD, S Bretagne MD); Westerdijk Fungal Biodiversity Institute, Utrecht, The Netherlands (A M S Al-Hatmi PhD); Centre of Expertise in Mycology RadboudUMC/Canisius Wilhelmina Hospital, Nijmegen, The Netherlands (A M S Al-Hatmi); Ministry of Health, Directorate General of Health Services, Ibri, Oman (A M S Al-Hatmi PhD); Department of Medical Microbiology, Hacettepe University School of Medicine, Sıhhiye Ankara, Turkey (S Arikan-Akdagli MD); Department of Medical Mycology/Invasive Fungi Research Center (IFRC), School of Medicine, Mazandaran University of Medical Sciences, Sari, Iran (H Badali PhD, S Seyedmousavi PhD); Sackler Faculty of Medicine, Tel Aviv University, Tel Aviv, Israel (R Ben-Ami MD); Infectious Diseases Unit, Tel Aviv Medical Center, Tel- Aviv, Israel (R BenAmi); Dermatology Service \& Mycology Department, Hospital General de México "Dr. Eduardo Liceaga", Mexico City, Mexico (A Bonifaz MD); Infectious Diseases Unit, Istituto Giannina Gaslini Children's Hospital, Genoa, Italy (E Castagnola MD); Department of Medicine, Faculty of Medicine Siriraj Hospital, Mahidol University, Bangkok, Thailand (M Chayakulkeeree MD); Special Mycology Laboratory, Division of Infectious Diseases, Department of Medicine, Universidade Federal de São Paulo (UNIFESP), São Paulo, Brazil (A L Colombo MD); Department of Epidemiology and Infectious Diseases, Hospital General Dr Manuel Gea González, Mexico City, Mexico (D E Corzo-Leon MD); Medical Mycology and Fungal Immunology/Wellcome Trust Strategic Award Program, Aberdeen Fungal Group, University of Aberdeen, King's College, Aberdeen, UK (D E Corzo-Leon MD); Oncohematology Clinic, Faculty of Medicine, Comenius University and National Cancer Institute, Bratislava, Slovakia (L Drgona MD); InfectiousDisease Research Program, Department of Paediatric Hematology/Oncology and Center for Bone Marrow Transplantation, University Children's Hospital Münster, Münster, Germany (A H Groll MD); Clinical Microbiology and Infectious Diseases, Hospital General Universitario Gregorio Marañón, Madrid, Spain (J Guinea PharmD); Instituto de Investigación v Sanitaria Gregorio Marañón, Madrid, Spain (J Guinea); Medicine Department, School of Medicine, Universidad Complutense 
de Madrid, Madrid, Spain (J Guinea PharmD); Diagnostic and Interventional Radiology, Thoracic Clinic, University Hospital Heidelberg, Heidelberg, Germany (C-P Heussel MD); Division of Infectious Diseases, Los Angeles Biomedical Research Institute at Harbor-University of California at Los Angeles (UCLA) Medical Center, Torrance, CA, USA (A S Ibrahim PhD); Department of Internal Medicine, Division of Infectious Diseases, American University of Beirut Medical Center, Beirut, Lebanon (S S Kanj MD); Department of Clinical Mycology, Allergology and Immunology, North Western State Medical University, St Petersburg, Russia (N Klimko MD); Division of Hygiene and Medical Microbiology, Department of Hygiene, Microbiology and Public Health, Medical University Innsbruck, Innsbruck, Austria (M Lackner MD, C Lass-Floerl MD); Infectious Diseases Service, Department of Medicine and Institute of Microbiology, Lausanne University Hospital, Lausanne, Switzerland (F Lamoth MD); Institute of Microbiology, Department of Laboratories, Lausanne University Hospital, Lausanne, Switzerland (F Lamoth); Institut Pasteur, National Reference Center for Invasive Mycoses and Antifungals, Department of Mycology, Paris Descartes University, NeckerEnfants Malades University Hospital, Department of Infectious Diseases and Tropical Medicine, Centre d'Infectiologie Necker-Pasteur, Institut Imagine, APHP, Paris, France (Lanternier MD); Division of Infectious Diseases, Department of Internal Medicine, Catholic Hematology Hospital, College of Medicine, The Catholic University of Korea, Seocho-gu, Seoul, Korea (D-G Lee MD); Division of Paediatric Haematology and Oncology, Hospital for Children and Adolescents, Johann Wolfgang Goethe-University, Frankfurt, Germany ( $T$ Lehrnbecher MD); School of Medicine and Pharmacy, University Mohammed the fifth, Hay Riad, Rabat, Morocco (B E Lmimouni MD); Laboratory of Antimicrobial Chemotherapy, Ion lonescu de la Brad University, lași, Romania (M Mares PhD); Department of Hematology, Oncology and Palliative Care, Klinikum Ernst von Bergmann, Potsdam, Germany (G Maschmeyer MD); Department of Medical Microbiology and Infectious Diseases, Centre of Expertise in Mycology Radboudumc/Canisius Wilhelmina Hospital, Nijmegen, Netherlands (J F Meis MD); Clinical Microbiology Laboratory, Attikon University Hospital, National and Kapodistrian University of Athens, Athens, Greece (J Meletiadis PhD); Department of Medical Microbiology and Infectious Diseases, Erasmus Medical Center, Rotterdam, The Netherlands (J Meletiadis $\mathrm{PhD}$ ); Department of Infectious Diseases, Alfred Health \& Monash University, Melbourne, Australia (C O Morrissey PhD); Department of Internal Medicine, Universidade Federal do Rio de Janeiro, Rio de Janeiro, Brazil (M Nucci MD); Department of Medical Microbiology \& Parasitology, College of Medicine, University of Lagos, Yaba, Lagos, Nigeria (R Oladele MD); Faculty of Biology, Medicine and Health, The University of Manchester, Manchester, UK (R Oladele MD); Department of Hematology, Fondazione Policlinico Universitario A. Gemelli -IRCCS- Universita Cattolica del Sacro Cuore, Roma, Italy (L Pagano MD); Federal University of Health Sciences of Porto Alegre, Hospital Dom Vicente Scherer, Porto Alegre, Brazil (A Pasqualotto 
$M D)$; Infectious Diseases Clinic, Vedanta Institute of Medical Sciences, Navarangpura, Ahmeddabad, India (A Patel MD); Institute of Hematology and Blood Transfusion, Prague, Czech Republic (Z Racil MD); UK NHS Mycology Reference Centre, Manchester University NHS Foundation Trust, Manchester, UK (M Richardson PhD); Hämatologie \& Internistische Onkologie, LukasKrankenhaus Bünde, Onkologische Ambulanz, Bünde, Germany (M Ruhnke $\mathrm{MD}$ ); Center of Expertise in Microbiology, Infection Biology and Antimicrobial Pharmacology, Tehran, Iran (S Seyedmousavi PhD); Molecular Microbiology Section, Laboratory of Clinical Immunology and Microbiology, National Institute of Allergy and Infectious Diseases, National Institutes of Health, Bethesda, MD, USA (S Seyedmousavi); Department of Hemato Oncology, Amrita Institute of Medical Sciences, Amrita Viswa Vidyapeetham University, Kochi, India (N Sidharthan MD); Division of Infectious Diseases, University of Pittsburgh Medical Center and VA Pittsburgh Healthcare System, Infectious Diseases Section, University of Pittsburgh, Pittsburgh, PA, USA (N Singh MD); Infectious Diseases Unit, Szent Istvan and Szent Laszlo Hospital, Budapest, Hungary (J Sinko MD); Department of Infectious Diseases, Laiko General Hospital, National and Kapodistrian University of Athens, Athens, Greece (A Skiada MD); University of Melbourne, Melbourne, VIC, Australia (M Slavin MD); The National Centre for Infections in Cancer, Peter MacCallum Cancer Centre, Parkville, Melbourne, VIC, Australia (M Slavin); P D Hinduja Hospital \& Medical Research Centre, Department of Medicine, Veer Sarvarkar Marg, Mumbai, India (R Soman MD); Los Angeles County and University of Southern California (LAC+USC) Medical Center, Los Angeles, CA, USA (B Spellberg MD); Division of Pediatric Infectious Diseases, Department of Pediatrics, Duke University Medical Center, Durham, NC, USA (W Steinbach MD); Department of Infectious Diseases, Singapore General Hospital, Singapur, Singapore (B H Tan MD); Department for Internal Medicine II, University Hospital Würzburg, Würzburg, Germany (A J Ullmann MD); Department of Internal Medicine, Hematology/Oncology, Goethe University Frankfurt, Frankfurt, Germany ( $\mathrm{J}$ Vehreschild); Department of Internal Medicine, Infectious Diseases, Goethe University Frankfurt, Frankfurt, Germany (M J G T Vehreschild); Departments of Medicine, Pediatrics, Microbiology \& Immunology, Weill Cornell Medicine, and New York Presbyterian Hospital, New York City, NY, USA (T J Walsh MD); Public Health Wales Microbiology Cardiff, UHW, Heath Park, Cardiff, UK (P L White PhD); Fungus Testing Laboratory, University of Texas Health Science Center, San Antonio, TX, USA (N P Wiederhold PharmD); and Division of Infectious Diseases, The Children's Hospital of Philadelphia, Philadelphia, PA, USA (T Zaoutis MD)

\section{Acknowledgments}

The following authors are fellows of the European Confederation of Medical Mycology (ECMM): OAC, AAI, SCAC, ED, BH, MH, HEJ, KL, DCS, AC, MA, AA, AMSA, SAA, HB, SB, MC, ALC, LD, AHG, ASI, SSK, NK, ML, FL, FL, CLF, MM, GM, JFM, JM, COM, MN, RO, LP, AP, MR, ER, SS, JS, JJV, MJGTV, TJW, PLW, and NPW. The following authors are members of the Mycoses Study Group and Research Consortium (MSG ERC): OAC, SCAC, DCS, ASI, BS, WS, TJW, NPW, TZ. The following authors are members of the Excellence Center 
(EC) for Medical Mycology of the European Confederation of Medical Mycology (ECMM): OAC, DA, SCM, DS, JJV, MJGTV, KL, ML, CL-F, JFM, and MR. We thank Valentina Arsic Arsenijevic, Neoh Chin Fen, and Adilia Warris for review and valuable contributions to the manuscript. The authors are indebted to Kerstin Albus, Susann Blossfeld, and Jon Salmanton-Garcia for technical support with this manuscript.

\section{Declaration of interests}

OAC reports research grants from Actelion, Amplyx, Arsanis, Astellas, AstraZeneca, Basilea, Bayer, Cidara, F2G, Gilead, GSK, Leeds University, Matinas, Medicines Company, MedPace, Melinta, Merck/MSD, Miltenyi, Pfizer, Rempex, Roche, Sanofi Pasteur, Scynexis, Seres; is a consultant to Allecra Therapeutics, Amplyx, Actelion, Astellas, Basilea, Cidara,Da Volterra, Entasis Therapeutics, F2G, Gilead, IQVIA, Janssen, Matinas, Menarini, Merck/MSD, Paratek, PSI, Scynexis, Seres, Summit, Tetraphase, Vical, and received lecture honoraria from Astellas, Basilea, Gilead, Merck/MSD and Pfizer ED reports grants from Gilead, MSD; personal fees from Pfizer, Astellas; non-financial support from MSD and Pfizer. AM reports grants from Sanofi and ROCHE. AAI reports grants and personal fees from GILEAD, personal fees from Pfizer, grants from F2G, grants from Scynexis, personal fees from Astellas, personal fees from MSD. SAA reports grants from Pfizer. SCAC reports grants from MSD Australia. MH reports reports personal fees from Basilea, Merck, Practitioner Network; and grants and personal fees from Gilead. KL reports grants, personal fees, and non-financial support from MSD, Gilead, and Pfizer; and personal fees from Abbott. REL reports personal fees from Gilead and grants from Merck. DCS reports grants from Merck and personal fees from Merck, Astellas, and AVIR. AA reports non-financial support from MSD, Gilead, and Pfizer; and personal fees from Gilead sciences and Pathoquest. RB reports grants and personal fees from Merck and Pfizer. SB reports grants from MSD; personal fees from Gilead and other from Pfizer. EC reports personal fees from Astellas and Basilea. MC reports personal fees from Astellas, Pfizer, LF Asia, Meiji, and MSD, and non-financial support from Astellas, Pfizer, and LF Asia. ALC reports grants from Astellas; grants, personal fees, and non-financial support from Pfizer; personal fees and non-financial support from Biotoscana; personal fees and non-financial support from MSD; and personal fees and non-financial support from Gilead. LD reports personal fees and non-financial support from MSD and Pfizer; and non-financial support from Teva. AHG reports grants and personal fees from Gilead, Merck, Sharp \& Dohme, and Pfizer; and personal fees from Astellas and Basilea. JG reports grants from Scynexis, CIDARA; and personal fees from Gilead, Pfizer, Astellas, MSD, and United Medical. $\mathrm{CPH}$ reports personal fees from Schering-Plough; grants and personal fees from Pfizer, Boehringer Ingelheim, Siemens; personal fees from Basilea, Novartis, Roche, Astellas, Gilead, MSD, Lilly, Intermune, Fresenius, Essex, AstraZeneca, Bracco, MEDA Pharma, Chiesi, Covidien, Pierre Fabre, Grifols, Bayer; and grants from MeVis, German Center for Lung Research. ASI reports grants from Amplyx Pharmaceuticals, grants from Astellas Pharma USA and is founder and shareholder from Vitalex Biosciences. NK reports personal fees from Astellas, Gilead, Merck, and Pfizer. FLan reports personal fees from Gilead, MSD, and Basilea. CLF reports reports grants from Gilead and Astellas; and personal fees from Gilead, Merck Sharp \& Dohme, Basilea. DGL reports consultant fees from Astellas, GILEAD, MSD, Pfizer, and Yuhan; has served as a board member for Gilead and Yuhan; and has received research support, travel support and payment for lectures, including service on Speaker's bureaus, from Astellas, GILEAD, MSD, Pfizer, and Yuhan. TL reports grants from Gilead; personal fees and non-financial support from Gilead, Astellas, and MSD; and personal fees from Basilea. GM reports personal fees from Gilead and Pfizer. JFM reports personal fees from Scynexis, Gilead, Merck, United Medical, and Teva; grants from F2G, Pulmocide, and Amplyx. JM reports grants from Astellas, Gilead, MSD, and Pfizer. COM reporsts grants from Gilead and Merck. MN reports grants from Pfizer; and personal fees from Gilead, Scynexis, Cidara, Teva, United Medical, MSD, and Jansen. LP reports grants from Gilead, MSD, and Pfizer. APas reports grants from Gilead; and personal fees from Gilead, United Medical. ZR reports grants from Astellas and Teva. MRi reports personal fees from Gilead, MSD, and Basilea. ER reports grants from Gilead, Pfizer, Merck, and Sanofi; personal fees and non-financial support from Pfizer, Merck, and Astellas. MRu reports personal fees from Scynexis, Daiichi Sankyo, and Kedplasma GmbH. JS reports personal fees from Pfizer and MSD. MS reports grants and personal fees from Gilead and Merck. BS reports personal fees from Cempra, Bayer, Forge, Shionogi, Alexion, Synthetic Biologics, Paratek, Ovagene, Accuryx, and Bioversys; and is shareholder for Motif, BioAIM, Synthetic Biologics, Mycomed, and ExBaq. WS reports fees from Astellas and Merck. BHT reports grants from Pfizer. AJU reports personal fees from MSD, Basilea, and Aicuris. JJV reports personal fees from Merck/MSD, Gilead, Pfizer, Astellas Pharma, Basilea, Deutsches Zentrum für Infektionsforschung, Uniklinik Freiburg/Kongress und Kommunikation, Akademie für Infektionsmedizin, Universität Manchester, Deutsche Gesellschaft für Infektiologie, Ärztekammer Nordrhein, Uniklinik Aachen, Back Bay Strategies, and Deutsche Gesellschaft für Innere Medizin; and grants from Merck/ MSD, Gilead, Pfizer, Astellas Pharma, Basilea, Deutsches Zentrum für Infektionsforschung, Bundesministerium für Bildung und Forschung. MJGTV reports having been on speakers' bureau for Pfizer, MSD/Merck, Gilead Sciences, Organobalance and Astellas Pharma; received research funding from 3M, Astellas Pharma, DaVolterra and Gilead Sciences; and is a consultant to Berlin Chemie, MSD/Merck and Astellas Pharma. TJW reports grants from Amplyx, Astellas, Merck, Scynexis, Allergan, Medicines Company, Lediant, and Tetraphase; and having served on Advisory Boards of Astellas, Merck, Scynexis, Allergan, Medicines. PLW reports personal fees from Gilead, MSD; and grants from Bruker. NPW reports grants from Astellas, bioMerieux, F2G, and Viamet; and personal fees from Mayne Pharma. All other authors declare no competing interests. 


\section{References}

1. Chamilos G, Lewis RE, Kontoyiannis DP. Delaying amphotericin B-based frontline therapy significantly increases mortality among patients with hematologic malignancy who have zygomycosis. Clin Infect Dis 2008; 47: 503-09. [PubMed: 18611163]

2. Vaughan C, Bartolo A, Vallabh N, Leong SC. A meta-analysis of survival factors in rhino-orbitalcerebral mucormycosis-has anything changed in the past 20 years? Clin Otolaryngol 2018; 43: 1454-64. [PubMed: 29947167]

3. Sun HY, Singh N. Mucormycosis: its contemporary face and management strategies. Lancet Infect Dis 2011; 11: 301-11. [PubMed: 21453871]

4. Tissot F, Agrawal S, Pagano L, et al. ECIL-6 guidelines for the treatment of invasive candidiasis, aspergillosis and mucormycosis in leukemia and hematopoietic stem cell transplant patients. Haematologica 2017; 102: 433-44. [PubMed: 28011902]

5. Kung HC, Huang PY, Chen WT, et al. 2016 guidelines for the use of antifungal agents in patients with invasive fungal diseases in Taiwan. J Microbiol Immunol Infect 2018; 51: 1-17. [PubMed: 28781150]

6. Cornely OA, Arikan-Akdagli S, Dannaoui E, et al. ESCMID and ECMM joint clinical guidelines for the diagnosis and management of mucormycosis 2013. Clin Microbiol Infect 2014; 20: 5-26.

7. Blyth CC, Gilroy NM, Guy SD, et al. Consensus guidelines for the treatment of invasive mould infections in haematological malignancy and haemopoietic stem cell transplantation, 2014. Intern Med J 2014; 44: 1333-49. [PubMed: 25482744]

8. Skiada A, Lanternier F, Groll AH, et al. Diagnosis and treatment of mucormycosis in patients with hematological malignancies: guidelines from the 3rd European Conference on Infections in Leukemia (ECIL 3). Haematologica 2013; 98: 492-504. [PubMed: 22983580]

9. Cornely OA, Lass-Florl C, Lagrou K, Arsic-Arsenijevic V, Hoenigl M. Improving outcome of fungal diseases. Guiding experts and patients towards excellence. Mycoses 2017; 60: 420-25. [PubMed: 28497502]

10. Hoenigl M, Gangneux JP, Segal E, et al. Global guidelines and initiatives from the European Confederation of Medical Mycology to improve patient care and research worldwide: new leadership is about working together. Mycoses 2018; 61: 885-94. [PubMed: 30086186]

11. Roden MM, Zaoutis TE, Buchanan WL, et al. Epidemiology and outcome of zygomycosis: a review of 929 reported cases. Clin Infect Dis 2005; 41: 634-53. [PubMed: 16080086]

12. Prakash H, Ghosh AK, Rudramurthy SM, et al. A prospective multicenter study on mucormycosis in India: epidemiology, diagnosis, and treatment. Med Mycol 2019; 57: 395-402. [PubMed: 30085158]

13. Corzo-Leon DE, Chora-Hernandez LD, Rodriguez-Zulueta AP, Walsh TJ. Diabetes mellitus as the major risk factor for mucormycosis in Mexico: epidemiology, diagnosis, and outcomes of reported cases. Med Mycol 2018; 56: 29-43. [PubMed: 28431008]

14. Cuenca-Estrella M, Bernal-Martinez L, Isla G, Gomez-Lopez A, Alcazar-Fuoli L, Buitrago MJ. Incidence of zygomycosis in transplant recipients. Clin Microbiol Infect 2009; 15: 37-40.

15. Hibbett DS, Binder M, Bischoff JF, et al. A higher-level phylogenetic classification of the Fungi. Mycol Res 2007; 111: 509-47. [PubMed: 17572334]

16. Kwon-Chung KJ. Taxonomy of fungi causing mucormycosis and entomophthoramycosis (zygomycosis) and nomenclature of the disease: molecular mycologic perspectives. Clin Infect Dis 2012; 54: S8-S15. [PubMed: 22247451]

17. Skiada A, Pagano L, Groll A, et al. Zygomycosis in Europe: analysis of 230 cases accrued by the registry of the European Confederation of Medical Mycology (ECMM) Working Group on Zygomycosis between 2005 and 2007. Clin Microbiol Infect 2011; 17: 1859-67. [PubMed: 21199154]

18. Sridhara SR, Paragache G, Panda NK, Chakrabarti A. Mucormycosis in immunocompetent individuals: an increasing trend. J Otolaryngol 2005; 34: 402-06. [PubMed: 16343400]

19. Guinea J, Escribano P, Vena A, et al. Increasing incidence of mucormycosis in a large Spanish hospital from 2007 to 2015: Epidemiology and microbiological characterization of the isolates. PLoS One 2017; 12: e0179136. [PubMed: 28591186] 
20. Xhaard A, Lanternier F, Porcher R, et al. Mucormycosis after allogeneic haematopoietic stem cell transplantation: a French multicentre cohort study (2003-2008). Clin Microbiol Infect 2012; 18 : e396-400. [PubMed: 22672535]

21. Pagano L, Ricci P, Tonso A, et al. Mucormycosis in patients with haematological malignancies: a retrospective clinical study of 37 cases. Br J Haematol 1997; 99: 331-36. [PubMed: 9375750]

22. Hammer MM, Madan R, Hatabu H. Pulmonary mucormycosis: radiologic features at presentation and over time. AJR Am J Roentgenol 2018; 210: 742-47. [PubMed: 29470162]

23. Nam BD, Kim TJ, Lee KS, Kim TS, Han J, Chung MJ. Pulmonary mucormycosis: serial morphologic changes on computed tomography correlate with clinical and pathologic findings. Eur Radiol 2018; 28: 788-95. [PubMed: 28812135]

24. Wahba H, Truong MT, Lei X, Kontoyiannis DP, Marom EM. Reversed halo sign in invasive pulmonary fungal infections. Clin Infect Dis 2008; 46: 1733-37. [PubMed: 18419427]

25. Legouge C, Caillot D, Chretien ML, et al. The reversed halo sign: pathognomonic pattern of pulmonary mucormycosis in leukemic patients with neutropenia? Clin Infect Dis 2014;58: 672-78. [PubMed: 24352351]

26. Singla K, Samra T, Bhatia N. Primary cutaneous mucormycosis in a trauma patient with MorelLavallee lesion. Indian J Crit Care Med 2018; 22: 375-77. [PubMed: 29910552]

27. Neblett Fanfair R, Benedict K, Bos J, et al. Necrotizing cutaneous mucormycosis after a tornado in Joplin, Missouri, in 2011. N Engl J Med 2012; 367: 2214-25. [PubMed: 23215557]

28. Al-Tarrah K, Abdelaty M, Behbahani A, Mokaddas E, Soliman H, Albader A. Cutaneous mucormycosis postcosmetic surgery: a case report and review of the literature. Medicine (Baltimore) 2016;95: e4185. [PubMed: 27399143]

29. Warkentien T, Rodriguez C, Lloyd B, et al. Invasive mold infections following combat-related injuries. Clin Infect Dis 2012; 55: 1441-49. [PubMed: 23042971]

30. Rodriguez CJ, Tribble DR, Malone DL, et al. Treatment of suspected invasive fungal infection in war wounds. Mil Med 2018; 183: 142-46. [PubMed: 30189071]

31. Hay RJ. Mucormycosis: an infectious complication of traumatic injury. Lancet 2005; 365: 830-31. [PubMed: 15752513]

32. Jayasuriya NS, Tilakaratne WM, Amaratunga EA, Ekanayake MK. An unusual presentation of rhinofacial zygomycosis due to Cunninghamella sp in an immunocompetent patient: a case report and literature review. Oral Dis 2006; 12: 67-69. [PubMed: 16390472]

33. Wang Y, Zhu M, Bao Y, et al. Cutaneous mucormycosis caused by Rhizopus microsporus in an immunocompetent patient: a case report and review of literature. Medicine (Baltimore) 2018; 97: e11141. [PubMed: 29924015]

34. Jundt JS, Wong MEK, Tatara AM, Demian NM. Invasive cutaneous facial mucormycosis in a trauma patient. J Oral Maxillofac Surg 2018; 76: 1930. e1-5. [PubMed: 29458027]

35. Candoni A, Klimko N, Busca A, et al. Fungal infections of the central nervous system and paranasal sinuses in onco-haematologic patients. Epidemiological study reporting the diagnostictherapeutic approach and outcome in 89 cases. Mycoses 2019; 62: 252-60. [PubMed: 30565742]

36. Bae MS, Kim EJ, Lee KM, Choi WS. Rapidly progressive rhino-orbito-cerebralmucormycosis complicated with unilateral internal carotid artery occlusion: a case report. Neurointervention 2012; 7: 45-49. [PubMed: 22454785]

37. Vallverdu Vidal M, Iglesias Moles S, Palomar Martinez M. Rhino-orbital-cerebral mucormycosis in a critically ill patient. Med Intensiva 2017; 41: 509-10. [PubMed: 27207730]

38. Bhansali A, Bhadada S, Sharma A, et al. Presentation and outcome of rhino-orbital-cerebral mucormycosis in patients with diabetes. Postgrad Med J 2004; 80: 670-74. [PubMed: 15537854]

39. Goh LC, Shakri ED, Ong HY, et al. A seven-year retrospective analysis of the clinicopathological and mycological manifestations of fungal rhinosinusitis in a single-centre tropical climate hospital. J Laryngol Otol 2017; 131: 813-16. [PubMed: 28841131]

40. Thomson SR, Bade PG, Taams M, Chrystal V. Gastrointestinal mucormycosis. Br J Surg 1991; 78 : 952-54. [PubMed: 1913115]

41. Dekkers R, Verweij PE, Weemaes CM, Severijnen RS, Van Krieken JH, Warris A. Gastrointestinal zygomycosis due to Rhizopus microsporus var. rhizopodiformis as a manifestation of chronic granulomatous disease. Med Mycol 2008; 46: 491-94. [PubMed: 18608916] 
42. Roilides E, Zaoutis TE, Katragkou A, Benjamin DK Jr, Walsh TJ. Zygomycosis in neonates: an uncommon but life-threatening infection. Am J Perinatol 2009; 26: 565-73. [PubMed: 19391079]

43. Chugh KS, Sakhuja V, Gupta KL, et al. Renal mucormycosis: computerized tomographic findings and their diagnostic significance. Am J Kidney Dis 1993; 22: 393-97. [PubMed: 8372834]

44. Sharma R, Shivanand G, Kumar R, et al. Isolated renal mucormycosis: an unusual cause of acute renal infarction in a boy with aplastic anaemia. Br J Radiol 2006; 79: e19-21. [PubMed: 16823048]

45. Marak RS, Misra R, Ansari MS, et al. Successful medical management of renal zygomycosis: a summary of two cases and a review of the Indian literature. Med Mycol 2010; 48: 1088-95. [PubMed: 20367111]

46. Thomas AJ, Shah S, Mathews MS, Chacko N. Apophysomyces elegans - renal mucormycosis in a healthy host: a case report from south India. Indian J Med Microbiol 2008; 26: 269-71. [PubMed: 18695332]

47. Yu J, Li RY. Primary renal zygomycosis due to Rhizopus oryzae. Med Mycol 2006; 44: 461-66. [PubMed: 16882613]

48. Jianhong L, Xianliang H, Xuewu J. Isolated renal mucormycosis in children. J Urol 2004; 171 : 387-88. [PubMed: 14665938]

49. Marty FM, Ostrosky-Zeichner L, Cornely OA, et al. Isavuconazole treatment for mucormycosis: a single-arm open-label trial and case-control analysis. Lancet Infect Dis 2016; 16: 828-37. [PubMed: 26969258]

50. Shoham S, Magill SS, Merz WG, et al. Primary treatment of zygomycosis with liposomal amphotericin B: analysis of 28 cases. Med Mycol 2010; 48: 511-17. [PubMed: 19824881]

51. Legrand M, Gits-Muselli M, Boutin L, et al. Detection of circulating mucorales DNA in critically ill burn patients: preliminary report of a screening strategy for early diagnosis and treatment. Clin Infect Dis 2016; 63: 1312-17. [PubMed: 27535951]

52. Hong HL, Lee YM, Kim T, et al. Risk factors for mortality in patients with invasive mucormycosis. Infect Chemother 2013; 45: 292-98. [PubMed: 24396630]

53. Palejwala SK, Zangeneh TT, Goldstein SA, Lemole GM. An aggressive multidisciplinary approach reduces mortality in rhinocerebral mucormycosis. J Neurol Surg B 2016; 77: P088.

54. Walsh TJ, Skiada A, Cornely OA, et al. Development of new strategies for early diagnosis of mucormycosis from bench to bedside. Mycoses 2014; 57: 2-7. [PubMed: 25475924]

55. Abidi MZ, Sohail MR, Cummins N, et al. Stability in the cumulative incidence, severity and mortality of 101 cases of invasive mucormycosis in high-risk patients from 1995 to 2011:a comparison of eras immediately before and after the availability of voriconazole and echinocandin-amphotericin combination therapies. Mycoses 2014; 57: 687-98. [PubMed: 25040241]

56. Bitar D, Che D. [Epidemiology of mucormycosis in metropolitan France, 1997-2010]. Med Sci (Paris) 2013; 29: 7-12 (in French).

57. Guarner J, Brandt ME. Histopathologic diagnosis of fungal infections in the 21 st century. Clin Microbiol Rev 2011; 24: 247-80. [PubMed: 21482725]

58. Kung VL, Chernock RD, Burnham CD. Diagnostic accuracy of fungal identification in histopathology and cytopathology specimens. Eur J Clin Microbiol Infect Dis 2018; 37: 157-65. [PubMed: 29027030]

59. Chermetz M, Gobbo M, Rupel K, et al. Combined orofacial aspergillosis and mucormycosis: fatal complication of a recurrent paediatric glioma-case report and review of literature. Mycopathologia 2016; 181: 723-33. [PubMed: 27350324]

60. Davoudi S, Kasraianfard A, Ahmadinejad Z, et al. Cytomegalovirus reactivation and preemptive therapy after liver transplant. Exp Clin Transplant 2014; 12: 72-75. [PubMed: 24635797]

61. Dhaliwal HS, Singh A, Sinha SK, et al. Diagnosed only if considered: isolated renal mucormycosis. Lancet 2015; 385: 2322. [PubMed: 26088500]

62. Frater JL, Hall GS, Procop GW. Histologic features of zygomycosis: emphasis on perineural invasion and fungal morphology. Arch Pathol Lab Med 2001; 125: 375-78. [PubMed: 11231486]

63. Hoeppli RJC. Histological observations in experimental schistosomiasis japonica. Chin Med J (Engl) 1932; 46: 1179-86. 
64. Splendore A Sobre a cultura d'una nova especie de cogumello pathogenico. Revista de Sociedade Scientifica de Sao Paulo 1908; 62: 62-63.

65. Ben-Ami R, Luna M, Lewis RE, Walsh TJ, Kontoyiannis DP. A clinicopathological study of pulmonary mucormycosis in cancer patients: extensive angioinvasion but limited inflammatory response. J Infect 2009; 59: 134-8. [PubMed: 19576639]

66. Chakrabarti A, Chatterjee SS, Das A, et al. Invasive zygomycosis in India: experience in a tertiary care hospital. Postgrad Med J 2009; 85: 573-81. [PubMed: 19892892]

67. Ruping MJ, Heinz WJ, Kindo AJ, et al. Forty-one recent cases of invasive zygomycosis from a global clinical registry. J Antimicrob Chemother 2010; 65: 296-302. [PubMed: 20008047]

68. Jensen HE, Salonen J, Ekfors TO. The use of immunohistochemistry to improve sensitivity and specificity in the diagnosis of systemic mycoses in patients with haematological malignancies. $\mathrm{J}$ Pathol 1997; 181: 100-05. [PubMed: 9072010]

69. Jung J, Park YS, Sung H, et al. Using immunohistochemistry to assess the accuracy of histomorphologic diagnosis of aspergillosis and mucormycosis. Clin Infect Dis 2015; 61: 166470. [PubMed: 26240202]

70. Sunagawa K, Ishige T, Kusumi Y, et al. Renal abscess involving mucormycosis by immunohistochemical detection in a patient with acute lymphocytic leukemia: a case report and literature review. Jpn J Infect Dis 2013; 66: 345-47. [PubMed: 23883851]

71. Bernal-Martinez L, Buitrago MJ, Castelli MV, Rodriguez-Tudela JL, Cuenca-Estrella M. Development of a single tube multiplex real-time PCR to detect the most clinically relevant Mucormycetes species. Clin Microbiol Infect 2013; 19: e1-7. [PubMed: 22925434]

72. Drogari-Apiranthitou M, Panayiotides I, Galani I, et al. Diagnostic value of a semi-nested PCR for the diagnosis of mucormycosis and aspergillosis from paraffin-embedded tissue: a single center experience. Pathol Res Pract 2016; 212: 393-97. [PubMed: 26874574]

73. Ruangritchankul K, Chindamporn A, Worasilchai N, Poumsuk U, Keelawat S, Bychkov A. Invasive fungal disease in university hospital: a PCR-based study of autopsy cases. Int J Clin Exp Pathol 2015; 8: 14840-52. [PubMed: 26823814]

74. Salehi E, Hedayati MT, Zoll J, et al. Discrimination of aspergillosis, mucormycosis, fusariosis, and scedosporiosis in formalin-fixed paraffin-embedded tissue specimens by use of multiple real-time quantitative PCR assays. J Clin Microbiol 2016; 54: 2798-803. [PubMed: 27605714]

75. Springer J, Goldenberger D, Schmidt F, et al. Development and application of two independent real-time PCR assays to detect clinically relevant Mucorales species. J Med Microbiol 2016;65: 227-34. [PubMed: 26743820]

76. Springer J, Lackner M, Ensinger C, et al. Clinical evaluation of a Mucorales-specific real-time PCR assay in tissue and serum samples. J Med Microbiol 2016; 65: 1414-21. [PubMed: 27902424]

77. Zaman K, Rudramurthy SM, Das A, et al. Molecular diagnosis of rhino-orbito-cerebral mucormycosis from fresh tissue samples. J Med Microbiol 2017; 66: 1124-29. [PubMed: 28792370]

78. Schwarz P, Bretagne S, Gantier JC, et al. Molecular identification of Zygomycetes from culture and experimentally infected tissues. J Clin Microbiol 2006; 44: 340-49. [PubMed: 16455881]

79. Lass-Florl C, Resch G, Nachbaur D, et al. The value of computed tomography-guided percutaneous lung biopsy for diagnosis of invasive fungal infection in immunocompromised patients. Clin Infect Dis 2007; 45: e101-04. [PubMed: 17806041]

80. Lau A, Chen S, Sorrell T, et al. Development and clinical application of a panfungal PCR assay to detect and identify fungal DNA in tissue specimens. J Clin Microbiol 2007;45: 380-85. [PubMed: 17122000]

81. Rickerts V, Mousset S, Lambrecht E, et al. Comparison of histopathological analysis, culture, and polymerase chain reaction assays to detect invasive mold infections from biopsy specimens. Clin Infect Dis 2007; 44: 1078-83. [PubMed: 17366453]

82. Kasai M, Harrington SM, Francesconi A, et al. Detection of a molecular biomarker for zygomycetes by quantitative PCR assays of plasma, bronchoalveolar lavage, and lung tissue in a rabbit model of experimental pulmonary zygomycosis. J Clin Microbiol 2008;46: 3690-702. [PubMed: 18845827] 
83. Hrncirova K, Lengerova M, Kocmanova I, et al. Rapid detection and identification of mucormycetes from culture and tissue samples by use of high-resolution melt analysis. J Clin Microbiol 2010;48: 3392-94. [PubMed: 20592150]

84. Buitrago MJ, Bernal-Martinez L, Castelli MV, Rodriguez-Tudela JL, Cuenca-Estrella M. Performance of panfungal- and specific-PCR-based procedures for etiological diagnosis of invasive fungal diseases on tissue biopsy specimens with proven infection: a 7-year retrospective analysis from a reference laboratory. J Clin Microbiol 2014; 52: 1737-40. [PubMed: 24574295]

85. Alanio A, Garcia-Hermoso D, Mercier-Delarue S, et al. Molecular identification of Mucorales in human tissues: contribution of PCR electrospray-ionization mass spectrometry. Clin Microbiol Infect 2015; 21: 594.

86. Hayden RT, Qian X, Procop GW, Roberts GD, Lloyd RV. In situ hybridization for the identification of filamentous fungi in tissue section. Diagn Mol Pathol 2002; 11: 119-26. [PubMed: 12045716]

87. Nagao K, Ota T, Tanikawa A, et al. Genetic identification and detection of human pathogenic Rhizopus species, a major mucormycosis agent, by multiplex PCR based on internal transcribed spacer region of rRNA gene. J Dermatol Sci 2005; 39: 23-31. [PubMed: 15978416]

88. Bialek R, Konrad F, Kern J, et al. PCR based identification and discrimination of agents of mucormycosis and aspergillosis in paraffin wax embedded tissue. J Clin Pathol 2005; 58: 1180-84. [PubMed: 16254108]

89. Rickerts V, Just-Nubling G, Konrad F, et al. Diagnosis of invasive aspergillosis and mucormycosis in immunocompromised patients by seminested PCR assay of tissue samples. Eur J Clin Microbiol Infect Dis 2006; 25: 8-13. [PubMed: 16416267]

90. Hata DJ, Buckwalter SP, Pritt BS, Roberts GD, Wengenack NL. Real-time PCR method for detection of zygomycetes. J Clin Microbiol 2008; 46: 2353-58. [PubMed: 18480229]

91. Dannaoui E, Schwarz P, Slany M, et al. Molecular detection and identification of zygomycetes species from paraffin-embedded tissues in a murine model of disseminated zygomycosis:a collaborative European Society of Clinical Microbiology and Infectious Diseases (ESCMID) Fungal Infection Study Group (EFISG) evaluation. J Clin Microbiol 2010; 48: 2043-46. [PubMed: 20375233]

92. Hammond SP, Bialek R, Milner DA, Petschnigg EM, Baden LR, Marty FM. Molecular methods to improve diagnosis and identification of mucormycosis. J Clin Microbiol 2011; 49: 2151-53. [PubMed: 21508149]

93. Buitrago MJ, Aguado JM, Ballen A, et al. Efficacy of DNA amplification in tissue biopsy samples to improve the detection of invasive fungal disease. Clin Microbiol Infect 2013; 19: e271-77. [PubMed: 23464751]

94. Gade L, Hurst S, Balajee SA, Lockhart SR, Litvintseva AP. Detection of mucormycetes and other pathogenic fungi in formalin fixed paraffin embedded and fresh tissues using the extended region of 28S rDNA. Med Mycol 2017; 55: 385-95. [PubMed: 27630252]

95. Ghadi NG, Shokohi T, Seifi Z, et al. Identification of Mucorales in patients with proven invasive mucormycosis by polymerase chain reaction in tissue samples. Mycoses 2018; 1: 909-915.

96. Gomes MZ, Lewis RE, Kontoyiannis DP. Mucormycosis caused by unusual mucormycetes, nonRhizopus, -Mucor, and -Lichtheimia species. Clin Microbiol Rev 2011; 24: 411-45. [PubMed: 21482731]

97. Petraitis V, Petraitiene R, Antachopoulos C, et al. Increased virulence of Cunninghamella bertholletiae in experimental pulmonary mucormycosis: correlation with circulating molecular biomarkers, sporangiospore germination and hyphal metabolism. Med Mycol 2013; 51: 72-82. [PubMed: 22686246]

98. Lanternier F, Dannaoui E, Morizot G, et al. A global analysis of mucormycosis in France: the RetroZygo study (2005-2007). Clin Infect Dis 2012; 54: S35-43. [PubMed: 22247443]

99. Lu XL, Liu ZH, Shen YN, et al. Primary cutaneous zygomycosis caused by Rhizomucor variabilis: a new endemic zygomycosis? A case report and review of 6 cases reported from China. Clin Infect Dis 2009; 49: e39-43. [PubMed: 19566442]

100. Etienne KA, Gillece J, Hilsabeck R, et al. Whole genome sequence typing to investigate the apophysomyces outbreak following a tornado in Joplin, Missouri, 2011. PLoS One 2012; 7: e49989. [PubMed: 23209631] 
101. Garcia-Hermoso D, Criscuolo A, Lee SC, et al. Outbreak of invasive wound mucormycosis in a burn unit due to multiple strains of Mucor circinelloides $\mathrm{f}$. circinelloides resolved by whole-genome sequencing. MBio 2018; 9.

102. Rammaert B, Lanternier F, Zahar JR, et al. Healthcare-associated mucormycosis. Clin Infect Dis 2012; 54: S44-54. [PubMed: 22247444]

103. Cheng VC, Chan JF, Ngan AH, et al. Outbreak of intestinal infection due to Rhizopus microsporus. J Clin Microbiol 2009; 47: 2834-43. [PubMed: 19641069]

104. Lanternier F, Poiree S, Elie C, et al. Prospective pilot study of high-dose (10 mg/kg/day) liposomal amphotericin B (L-AMB)for the initial treatment of mucormycosis. J Antimicrob Chemother 2015; 70: 3116-23. [PubMed: 26316385]

105. Pagano L, Valentini CG, Posteraro B, et al. Zygomycosis in Italy:a survey of FIMUA-ECMM (Federazione Italiana di Micopatologia Umana ed Animale and European Confederation of Medical Mycology). J Chemother 2009; 21: 322-29. [PubMed: 19567354]

106. Cornely OA, Maertens J, Bresnik M, et al. Liposomal amphotericin B as initial therapy for invasive mold infection: a randomized trial comparing a high-loading dose regimen with standard dosing (AmBiLoad trial). Clin Infect Dis 2007; 44: 1289-97. [PubMed: 17443465]

107. Stanzani M, Vianelli N, Cavo M, Maritati A, Morotti M, Lewis RE. Retrospective cohort analysis of liposomal amphotericin b nephrotoxicity in patients with hematological malignancies. Antimicrob Agents Chemother 2017; 61.

108. Kyvernitakis A, Torres HA, Jiang Y, Chamilos G, Lewis RE, Kontoyiannis DP. Initial use of combination treatment does not impact survival of 106 patients with haematologic malignancies and mucormycosis: a propensity score analysis. Clin Microbiol Infect 2016; 22: 811.

109. Pagano L, Offidani M, Fianchi L, et al. Mucormycosis in hematologic patients. Haematologica 2004; 89: 207-14. [PubMed: 15003897]

110. Nosari A, Oreste P, Montillo M, et al. Mucormycosis in hematologic malignancies: an emerging fungal infection. Haematologica 2000; 85: 1068-71. [PubMed: 11025599]

111. Walsh TJ, Goodman JL, Pappas P, et al. Safety, tolerance, and pharmacokinetics of high-dose liposomal amphotericin B (AmBisome) in patients infected with Aspergillus species and other filamentous fungi: maximum tolerated dose study. Antimicrob Agents Chemother 2001; 45: 3487-96. [PubMed: 11709329]

112. Ibrahim AS, Gebremariam T, Husseiny MI, et al. Comparison of lipid amphotericin B preparations in treating murine zygomycosis. Antimicrob Agents Chemother 2008; 52: 1573-76. [PubMed: 18227182]

113. Larkin JA, Montero JA. Efficacy and safety of amphotericin B lipid complex for zygomycosis. Infect Med 2003; 20: 201-06.

114. Forrest GN, Mankes K. Outcomes of invasive zygomycosis infections in renal transplant recipients. Transpl Infect Dis 2007; 9: 161-64. [PubMed: 17462005]

115. Ullmann AJ, Sanz MA, Tramarin A, et al. Prospective study of amphotericin B formulations in immunocompromised patients in 4 European countries. Clin Infect Dis 2006; 43: e29-38. [PubMed: 16838223]

116. Walsh TJ, Finberg RW, Arndt C, et al. Liposomal amphotericin B for empirical therapy in patients with persistent fever and neutropenia. National Institute of Allergy and Infectious Diseases Mycoses Study Group. N Engl J Med 1999; 34: 764-71.

117. Roilides E, Antachopoulos C. Isavuconazole: an azole active against mucormycosis. Lancet Infect Dis 2016; 16: 761-62. [PubMed: 26969257]

118. Abuodeh RO, Galgiani JN, Scalarone GM. Molecular approaches to the study of Coccidioides immitis. Int J Med Microbiol 2002;292: 373-80. [PubMed: 12452283]

119. Mellinghoff SC, Bassetti M, Dorfel D, et al. Isavuconazole shortens the QTc interval. Mycoses 2017; 61: 256-260.

120. Maertens JA, Raad II, Marr KA, et al. Isavuconazole versus voriconazole for primary treatment of invasive mould disease caused by aspergillus and other filamentous fungi (SECURE): a phase 3, randomised-controlled, non-inferiority trial. Lancet 2016; 387: 760-69. [PubMed: 26684607]

121. DiPippo AJ, Rausch CR, Kontoyiannis DP. Tolerability of isavuconazole after posaconazole toxicity in leukemia patients. Mycoses 2018; 62: 81-86. [PubMed: 30230043] 
122. Duarte RF, Lopez-Jimenez J, Cornely OA, et al. Phase 1b study of new posaconazole tablet for prevention of invasive fungal infections in high-risk patients with neutropenia. Antimicrob Agents Chemother 2014; 58: 5758-65. [PubMed: 25049247]

123. Cornely OA, Duarte RF, Haider S, et al. Phase 3 pharmacokinetics and safety study of a posaconazole tablet formulation in patients at risk for invasive fungal disease. J Antimicrob Chemother 2016;71: 1747. [PubMed: 26960721]

124. Maertens J, Cornely OA, Ullmann AJ, et al. Phase 1B study of the pharmacokinetics and safety of posaconazole intravenous solution in patients at risk for invasive fungal disease. Antimicrob Agents Chemother 2014; 58: 3610-17. [PubMed: 24733463]

125. Cornely OA, Robertson MN, Haider S, et al. Pharmacokinetics and safety results from the phase 3 randomized, open-label, study of intravenous posaconazole in patients at risk of invasive fungal disease. J Antimicrob Chemother 2017; 72: 3406-13. [PubMed: 28961714]

126. Ibrahim AS, Gebremariam T, Fu Y, Edwards JE Jr, Spellberg B. Combination echinocandinpolyene treatment of murine mucormycosis. Antimicrob Agents Chemother 2008; 52: 1556-58. [PubMed: 18212099]

127. Ibrahim AS, Gebremariam T, Schwartz JA, Edwards JE Jr, Spellberg B. Posaconazole mono- or combination therapy for treatment of murine zygomycosis. Antimicrob Agents Chemother 2009; 53: 772-75. [PubMed: 18936190]

128. Klimko NN, Khostelidi SN, Volkova AG, et al. Mucormycosis in haematological patients: case report and results of prospective study in Saint Petersburg, Russia. Mycoses 2014; 57: 91-96. [PubMed: 25187314]

129. Reed C, Bryant R, Ibrahim AS, et al. Combination polyene-caspofungin treatment of rhinoorbital-cerebral mucormycosis. Clin Infect Dis 2008; 47: 364-71. [PubMed: 18558882]

130. Jenks JD, Reed SL, Seidel D, et al. Rare mold infections caused by Mucorales, Lomentospora prolificans and fusarium, San Diego:the role of antifungal combination therapy. Int J Antimicrob Agents 2018; 52: 706-12. [PubMed: 30099056]

131. Rodriguez CJ, Tribble DR, Malone DL, et al. Treatment of suspected invasive fungal infection in war wounds. Mil Med 2018; 183: 142-46. [PubMed: 30189071]

132. Marty FM, Cornely OA, Mullane KM, et al. Isavuconazole for treatment of invasive fungal diseases caused by more than one fungal species. Mycoses 2018; 61: 485-97. [PubMed: 29611227]

133. Greenberg RN, Mullane K, van Burik JA, et al. Posaconazole as salvage therapy for zygomycosis. Antimicrob Agents Chemother 2006; 50: 126-33. [PubMed: 16377677]

134. van Burik JA, Hare RS, Solomon HF, Corrado ML, Kontoyiannis DP. Posaconazole is effective as salvage therapy in zygomycosis:a retrospective summary of 91 cases. Clin Infect Dis 2006; 42: e61-65. [PubMed: 16511748]

135. Vehreschild JJ, Birtel A, Vehreschild MJ, et al. Mucormycosis treated with posaconazole: review of 96 case reports. Crit Rev Microbiol 2013; 39: 310-24. [PubMed: 22917084]

136. Walsh TJ, Hiemenz JW, Seibel NL, et al. Amphotericin B lipid complex for invasive fungal infections: analysis of safety and efficacy in 556 cases. Clin Infect Dis 1998; 26: 1383-96. [PubMed: 9636868]

137. Herbrecht R, Letscher-Bru V, Bowden RA, et al. Treatment of 21 cases of invasive mucormycosis with amphotericin B colloidal dispersion. Eur J Clin Microbiol Infect Dis 2001; 20: 460-66. [PubMed: 11561801]

138. Kim JH, Benefield RJ, Ditolla K. Utilization of posaconazole oral suspension or delayed-released tablet salvage treatment for invasive fungal infection. Mycoses 2016; 59: 726-33. [PubMed: 27392814]

139. Ma J, Jia R, Li J, et al. Retrospective clinical study of eighty-one cases of intracranial mucormycosis. J Glob Infect Dis 2015;7: 143-50. [PubMed: 26752868]

140. Davoudi S, Anderlini P, Fuller GN, Kontoyiannis DP. A long-term survivor of disseminated aspergillus and mucorales infection: an instructive case. Mycopathologia 2014; 178: 465-70. [PubMed: 25086667] 
141. Valentini CG, Candoni A, Fianchi L, et al. Efficacy of combined surgery and antifungal therapies for the management of invasive zygomycoses in patients with haematological malignancies. Mycoses 2010; 53: 89-92. [PubMed: 19207832]

142. Tedder M, Spratt JA, Anstadt MP, Hegde SS, Tedder SD, Lowe JE. Pulmonary mucormycosis: results of medical and surgical therapy. Ann Thorac Surg 1994; 57: 1044-50. [PubMed: 8166512]

143. Kontoyiannis DP, Lewis RE. How I treat mucormycosis. Blood 2011; 118: 1216-24. [PubMed: 21622653]

144. Gleissner B, Schilling A, Anagnostopolous I, Siehl I, Thiel E. Improved outcome of zygomycosis in patients with hematological diseases? Leuk Lymphoma 2004; 45: 1351-60. [PubMed: 15359632]

145. Singh N, Aguado JM, Bonatti H, et al. Zygomycosis in solid organ transplant recipients: a prospective, matched case-control study to assess risks for disease and outcome. J Infect Dis 2009; 200: 1002-11. [PubMed: 19659439]

146. Sun HY, Aguado JM, Bonatti H, et al. Pulmonary zygomycosis in solid organ transplant recipients in the current era. Am J Transplant 2009; 9: 2166-71. [PubMed: 19681829]

147. Lanternier F, Sun HY, Ribaud P, Singh N, Kontoyiannis DP, Lortholary O. Mucormycosis in organ and stem cell transplant recipients. Clin Infect Dis 2012; 54: 1629-36.

148. Li YH, Sun P, Guo JC. Clinical analysis of diabetic combined pulmonary mucormycosis. Mycopathologia 2017; 182: 1111-17. [PubMed: 28667347]

149. Dannaoui E, Meis JF, Loebenberg D, Verweij PE. Activity of posaconazole in treatment of experimental disseminated zygomycosis. Antimicrob Agents Chemother 2003; 47: 3647-50. [PubMed: 14576138]

150. Hirabayashi KE, Kalin-Hajdu E, Brodie FL, Kersten RC, Russell MS, Vagefi MR. Retrobulbar injection of amphotericin B for orbital mucormycosis. Ophthalmic Plast Reconstr Surg 2017; 33: e94-97. [PubMed: 27768642] 


\section{Panel: How the guideline group worked}

In December, 2017, experts were identified based on their publication activity in the field of mucormycosis in the previous 5 years, their involvement in patient management, and their distribution over world regions defined by the United Nations. Experts were invited to develop this guideline in January, 2018.

This guideline follows the structure and definitions of previous guidelines on invasive fungal infections which are in accordance with the Grading of Recommendations Assessment, Development and Evaluation (GRADE) and Appraisal of Guidelines for Research \& Evaluation (AGREE) systems. The PICO (population, intervention, comparison, and outcome) approach is reflected by the tables.

Both, diagnostic assays and treatment strategies might alter patient course, and are thus regarded as interventions. First, a population is defined; then the intention or objective is stated, followed by the intervention. For such logical sequence, strength of recommendation (SOR) and quality of evidence (QOE) are provided, followed by the references on which the recommendation is based. SOR and QOE are results of two independent evaluations, thus allowing a strong recommendation even in the absence of the highest quality evidence (table 1).

Search strings used were "mucormyc* OR zygomyc*", "cavernous sinus syndrome OR orbital apex syndrome AND etiology", and for the epidemiological section "mucormyc* OR zygomyc* AND (case*[Title/Abstract] OR patient*[Title/Abstract] OR report[Title/ Abstract]) AND (“2013/01/01”[PDat] : “2017/12/31”[PDat])”.

From January to February, 2018, video conferences on the methodology were held, and a video tutorial added in March, 2018. Assistance and supervision to the group were provided by the coordinators (OAC, AC). Documents were shared among the authors on a password-protected OneDrive (Microsoft Corp, Redmont WA, USA) repository, and were updated several times per day. Updates on PICO tables were written in red font; after spellcheck and formatting font colour was changed to blue for consideration by the group. Contents discussed and agreed on were changed to black font. Once all tables were finalised, a writing group (OAC, AAI, DA, SCAC, ED, BH, MH, HEJ, KL, REL, SCM, MMe, ZP, DS, DCS, RW, AC) contributed the first draft, which was circulated to all participants for approval in October, 2018. Recommendations were consensus-based. If no consensus was found, majority vote was used.

In November, 2018, a 4-week public consultation phase ensued. Comments received were evaluated, and either dismissed or used to change the manuscript, resulting in a final author review in December, 2018. 51 scientific societies from 33 countries reviewed and endorsed the guidance document. 

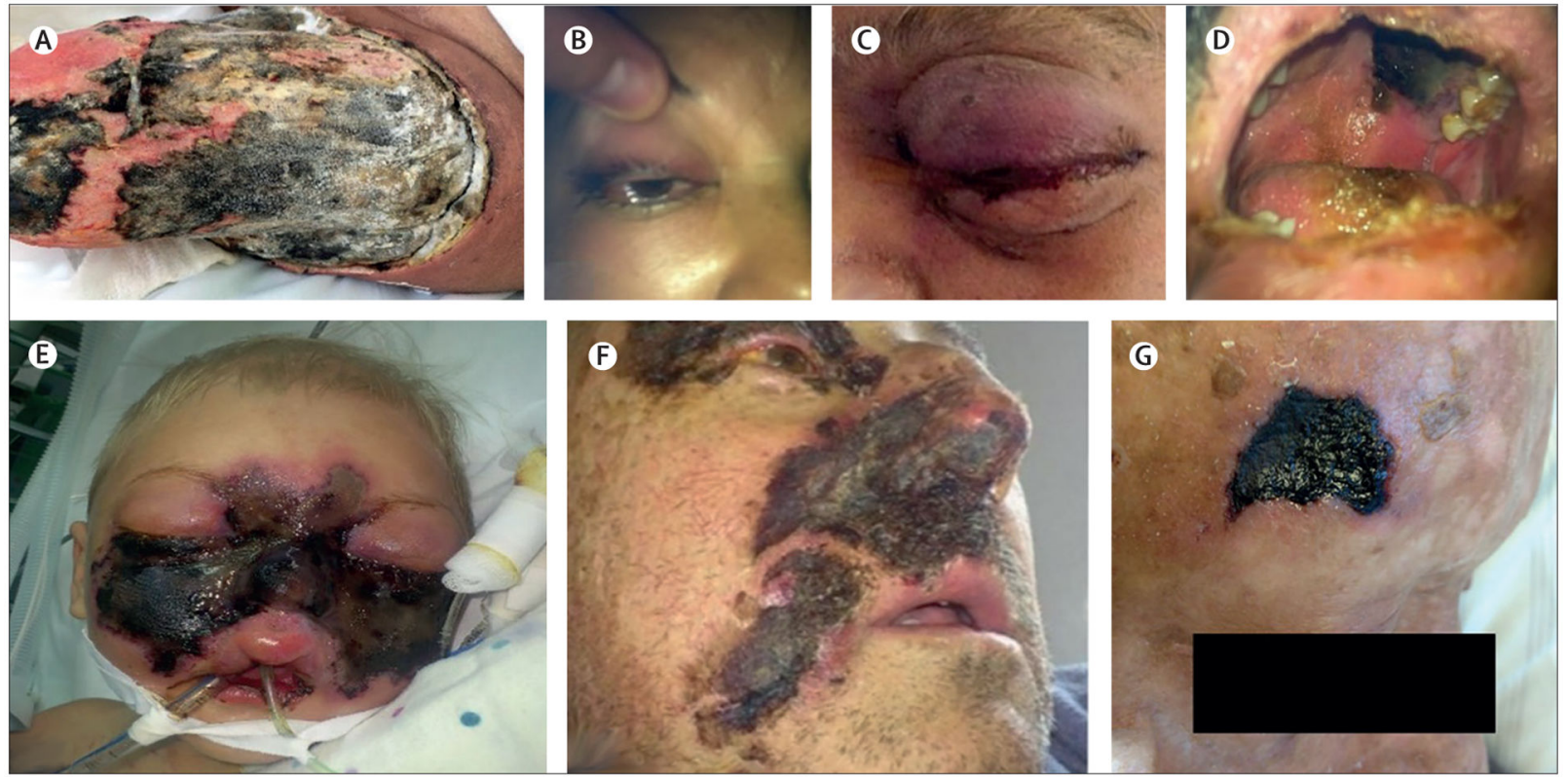

Figure 1: Cutaneous and rhino-orbito-cerebral mucormycosis

(A) Extensive primary cutaneous mucormycosis of the left leg due to Apophysomyces variabilis, after a car accident. (B) Erythematous skin, ptosis, palpebral oedema, limited ocular motility, and right maxillary pain, 6 days after symptom onset in uncontrolled diabetes. (C) Proptosis, palpebral erythema, and cavernous sinus syndrome, 7 days after symptom onset in uncontrolled diabetes. (D) Necrotic, purulent palatal ulcer and cavernous sinus syndrome, 8 days after symptom onset in uncontrolled diabetes. (E) Rhinocerebral mucormycosis in a female child, 2 years old with acute lymphoblastic leukaemia and lethal outcome. (F) 52-year-old man with persistent neutropenia post chemotherapy, sinusitis, and skin necrosis. (G) Black eschar as typical skin lesion in mucormycosis; one of several lesions on the right forehead, ear and cheek in a non-diabetic, haematopoietic stem cell transplant recipient with pansinusitis due to Lichtheimia corymbifera. Image A courtesy of Alexandro Bonifaz, images B-D courtesy of Dora E Corzo-León, images E and F courtesy of Valentina Arsic Arsenijevic, Belgrade, Serbia, and image G courtesy of University Hospital Cologne. We obtained written permission from patients or parents respectively to publish images, and from ethics committee as appropriate per local regulation. 


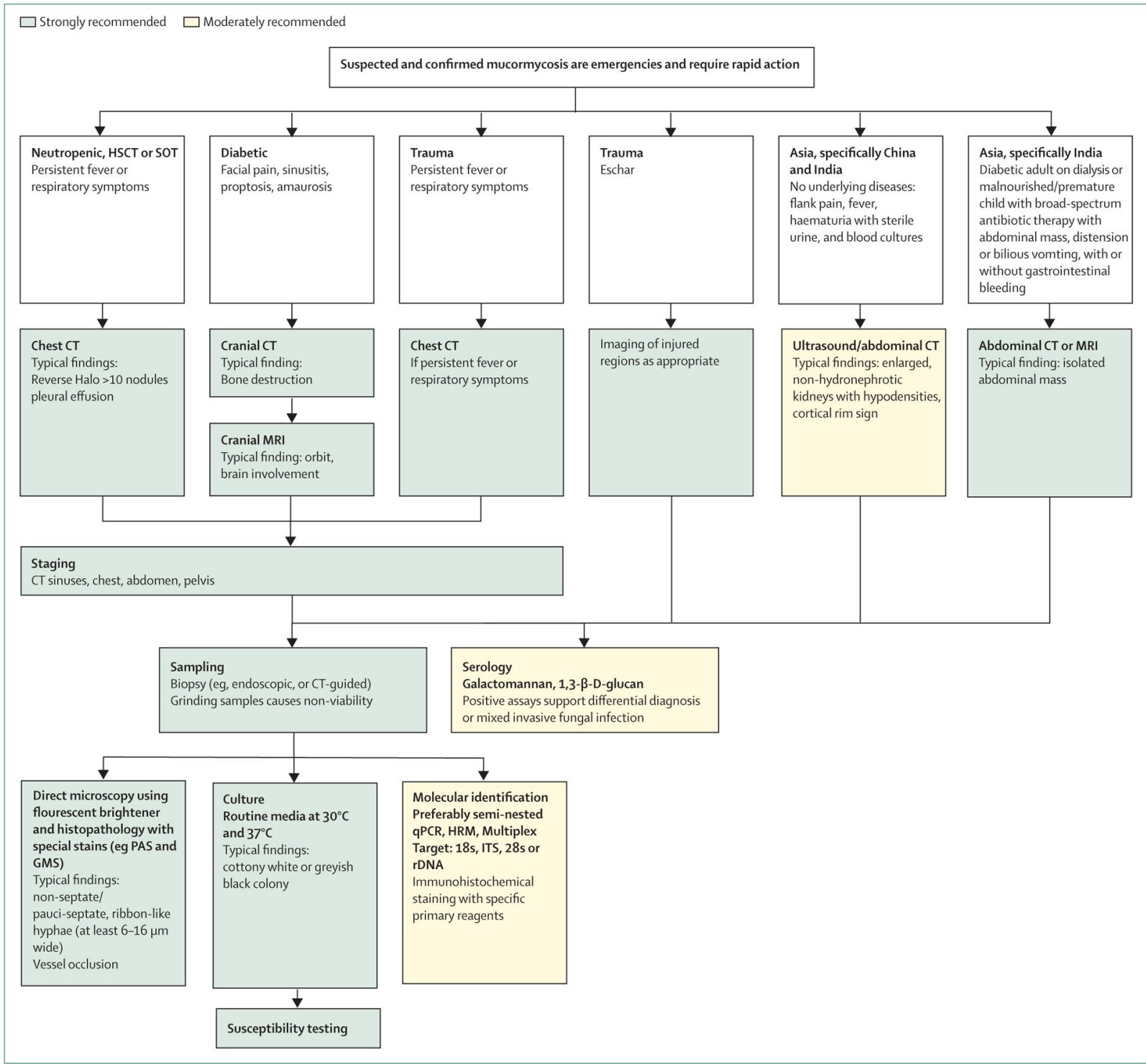

Figure 2: Diagnostic pathway for mucormycosis

Depending on the geographical location not all recommended tests might have regulatory approval for use in clinical settings. HSCT=haematopoietic stem cell translplantation. SOT=solid organ transplantation. PAS=periodic acid Schiff. GMS=Grocott-Gomori's methenamine-silver strain. qPCR=quantitative PCR. HRM=high resolution melting. ITS=internal transcribed spacer. rDNA=ribosomal DNA. 

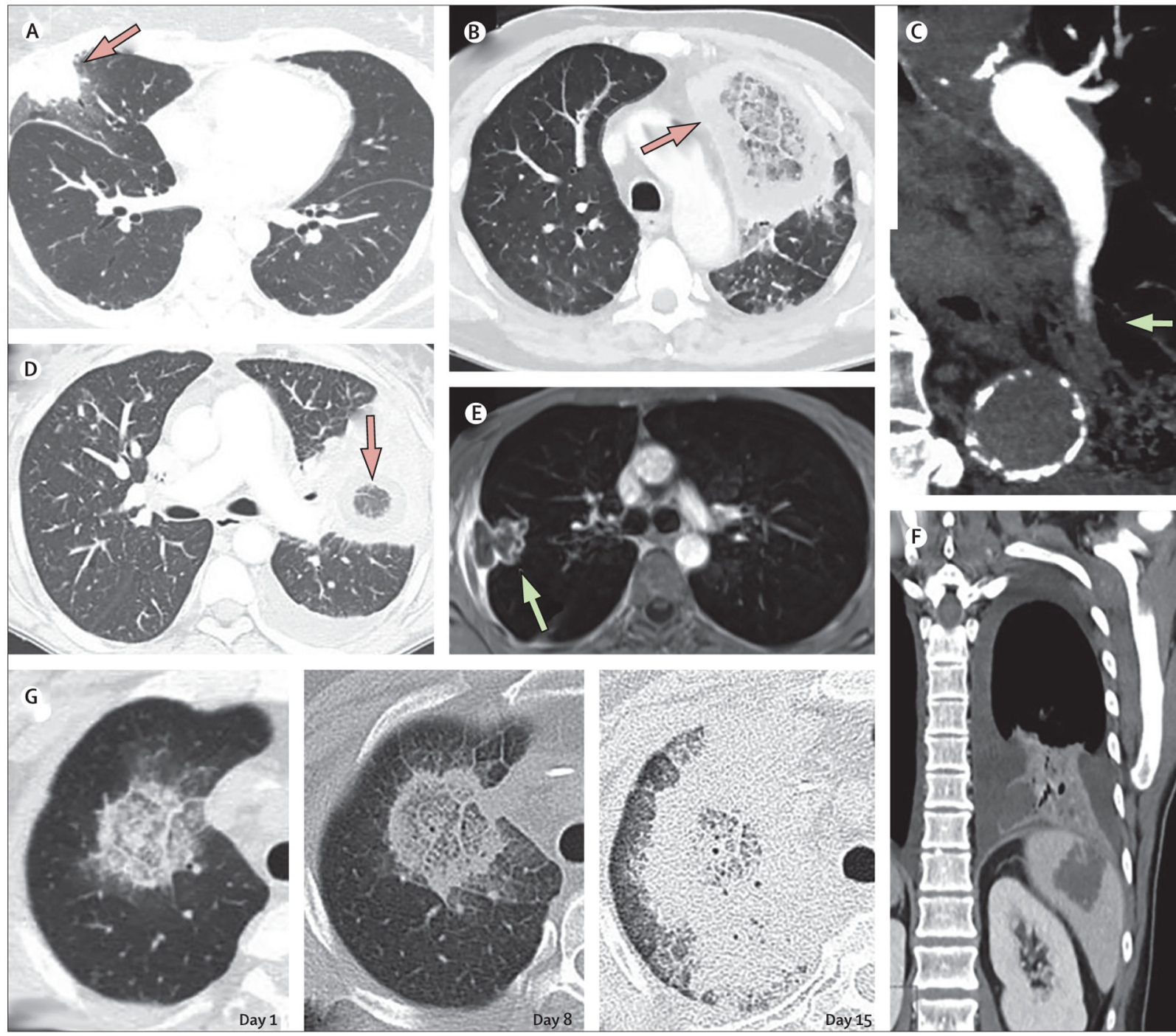

Figure 3: Radiographic signs of mucormycosis

Four imaging signs can suggest pulmonary mucormycosis in an appropriate clinical setting. (A) Halo sign on CT, a ring of ground glass opacity surrounding a nodular infiltrate, which pathophysiologically represents a region of ischaemia, and which is also typical of invasive pulmonary aspergillosis (arrow). (D \& B) Reversed halo sign on CT, also known as inversed halo or atoll sign, an area of ground glass opacity surrounded by a ring of consolidation (arrow). (E) Hypodense sign on MRI, T1 weighted, a central hypodensity in a lung consolidation or nodule, corresponding to a central area of necrosis caused by vascular obstruction with secondary lung infarction and sequestration. Magnetic resonance imaging shows pulmonary nodule with central hypodensity in right upper lobe (arrow), corresponding to a central area of necrosis caused by vascular obstruction with secondary lung infarct and sequestration. (C) Vascular occlusion sign on CT angiography, defined as interrupted vessel at the border of a focal lesion without depiction of the vessel inside the lesion or peripheral to the lesion (arrow). Particularly aggressive forms of mucormycosis are F. Contiguous spread on CT, presence of a mass or consolidation exhibiting invasion of 
adjacent organs by traversing tissue planes, including the diaphragm, chest wall, pleura, and spleen. (G) Typical rapidly progressive pulmonary mucormycosis on CT, associated with clinical deterioration. Day 8 and Day 15 CT scans showing a reversed halo sign. Images A, C, D, and E courtesy of Bruno Hochhegger, images B, F, and G courtesy of University Hospital Cologne. 

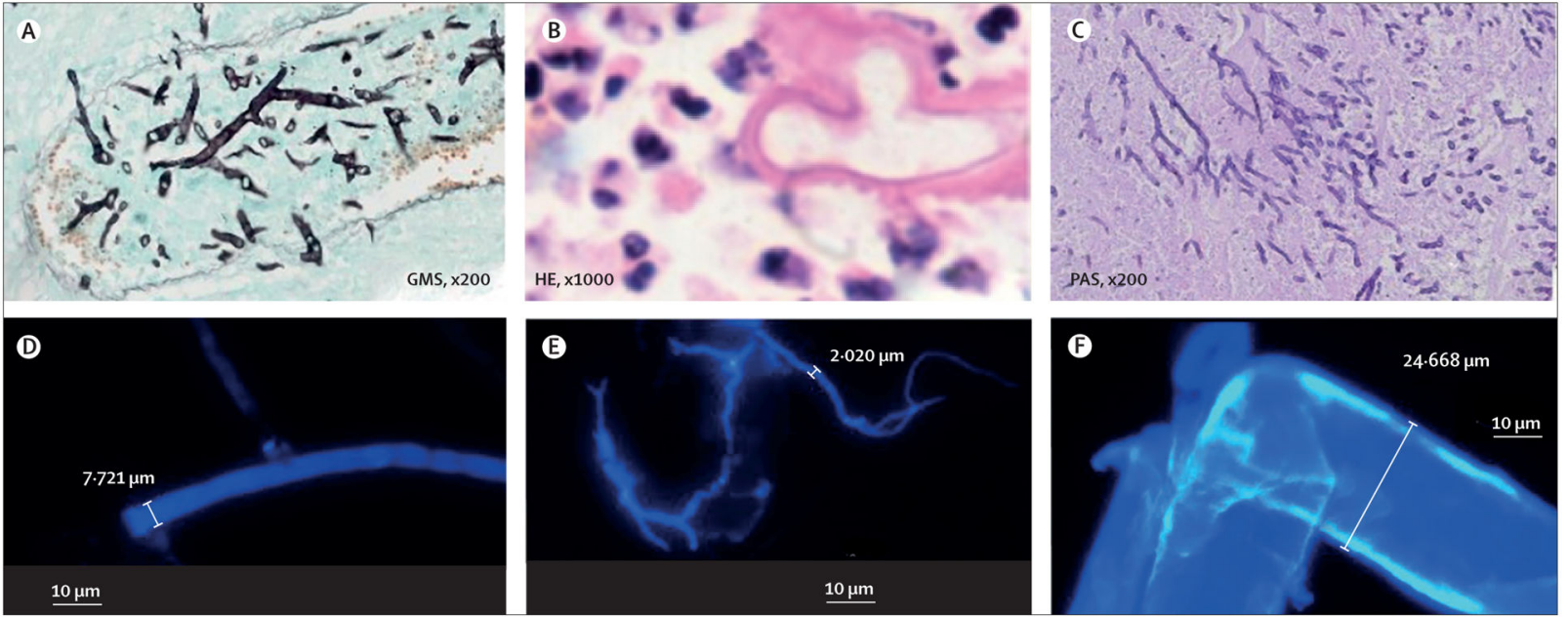

Figure 4: Hyphal morphology in mucormycosis and aspergillosis

(A) Typical hyphal morphology in mucormycosis lesions (GMS, × 200). Mucorales hyphae are at least 6-16 $\mu \mathrm{m}$ wide, ribbon-like, pauci-septate, and branch irregularly. (B) Hyphal structure covered with Splendore-Hoeppli phenomenon (HE, $\times 1000)$. The eosinophilic material likely represents antigen-antibody complexes. First described by Splendore in 1908, and by Hoeppli in 1932. (C) Typical hyphal morphology in aspergillosis lesions (PAS, $\times$ 200). Aspergillus hyphae are 3-5 $\mu \mathrm{m}$ wide, regularly septated, with dichotomous branching. (D-F) Sizes and branching angles for Mucorales and aspergillus stained by calcofluor-white. $\mathrm{D}$ and $\mathrm{F}$ correspond to Rhizopus arrhizus and $\mathrm{E}$ to Aspergillus fumigatus. Measurements correspond to the size of the white lines; hyphal diameter were performed with the Leica software LAS-AF and are expressed in $\mu \mathrm{m}$. Diagnosis needs to be confirmed by culture, molecular techniques, or both. Images A-C courtesy of Henrik E Jensen and images D-F courtesy of Ana Alastruey-Izquierdo. 
$\square$ Strongly recommended $\square$ Moderately recommended $\square$ Marginally recommended $\square$ Recommended against

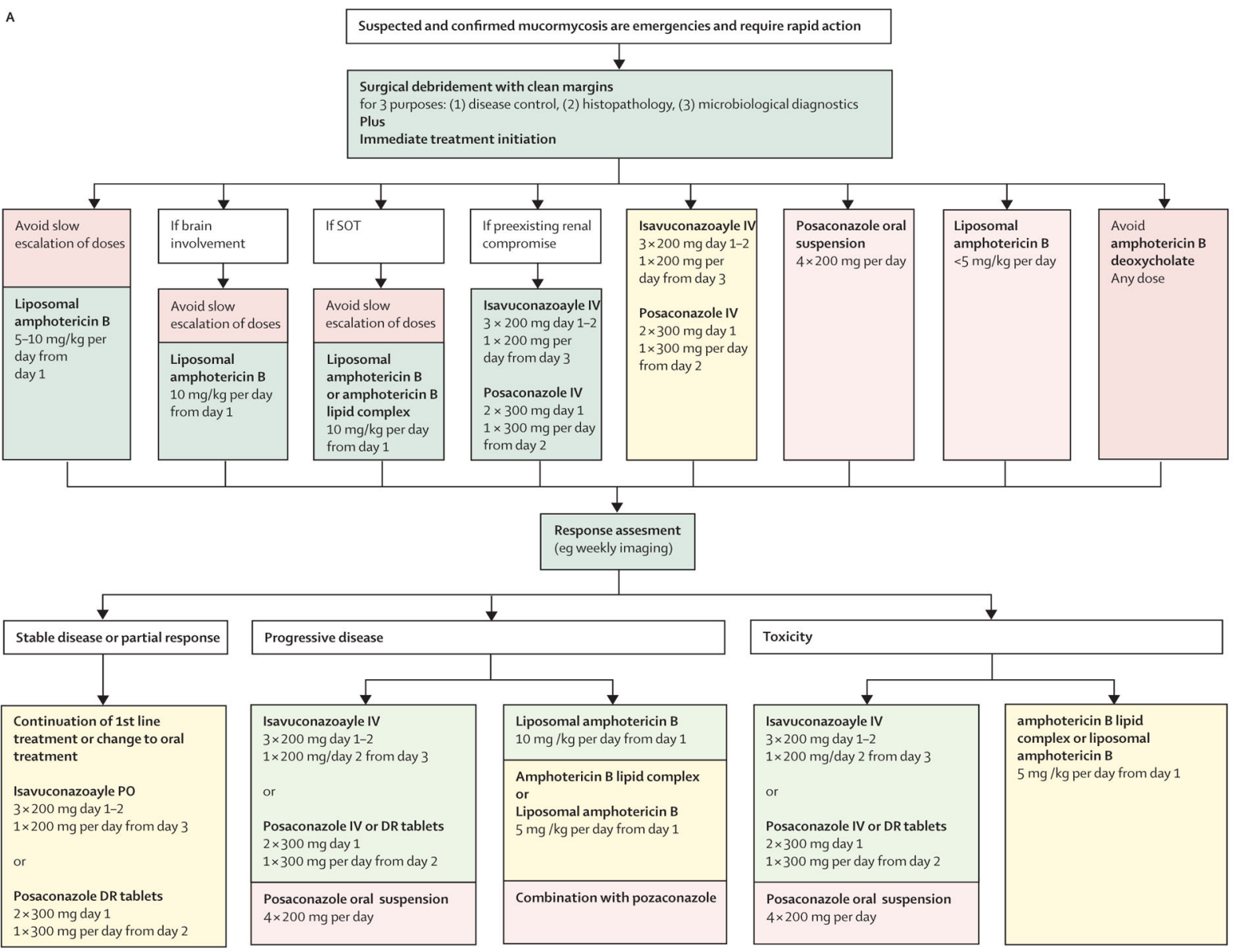

Lancet Infect Dis. Author manuscript; available in PMC 2021 November 01. 


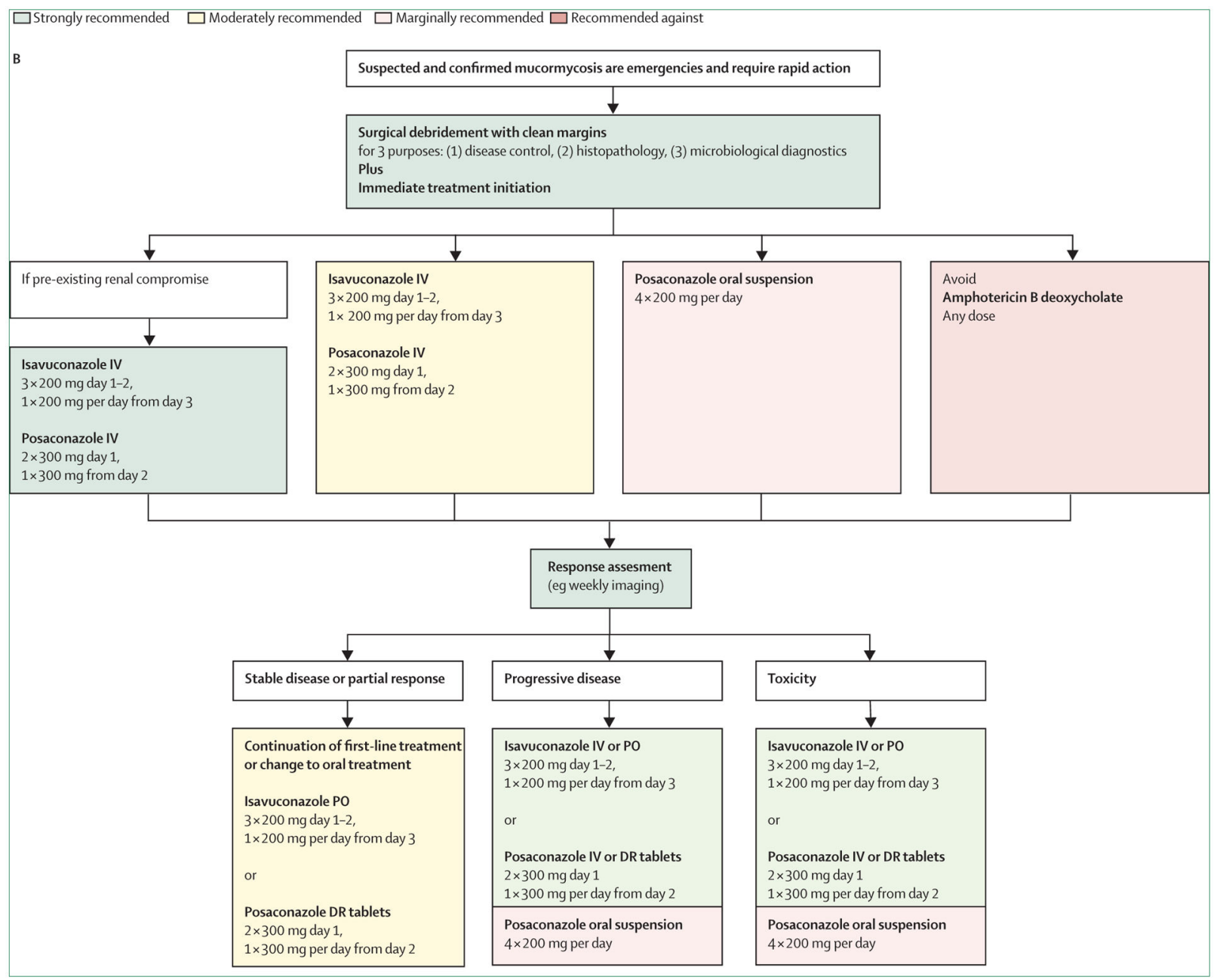




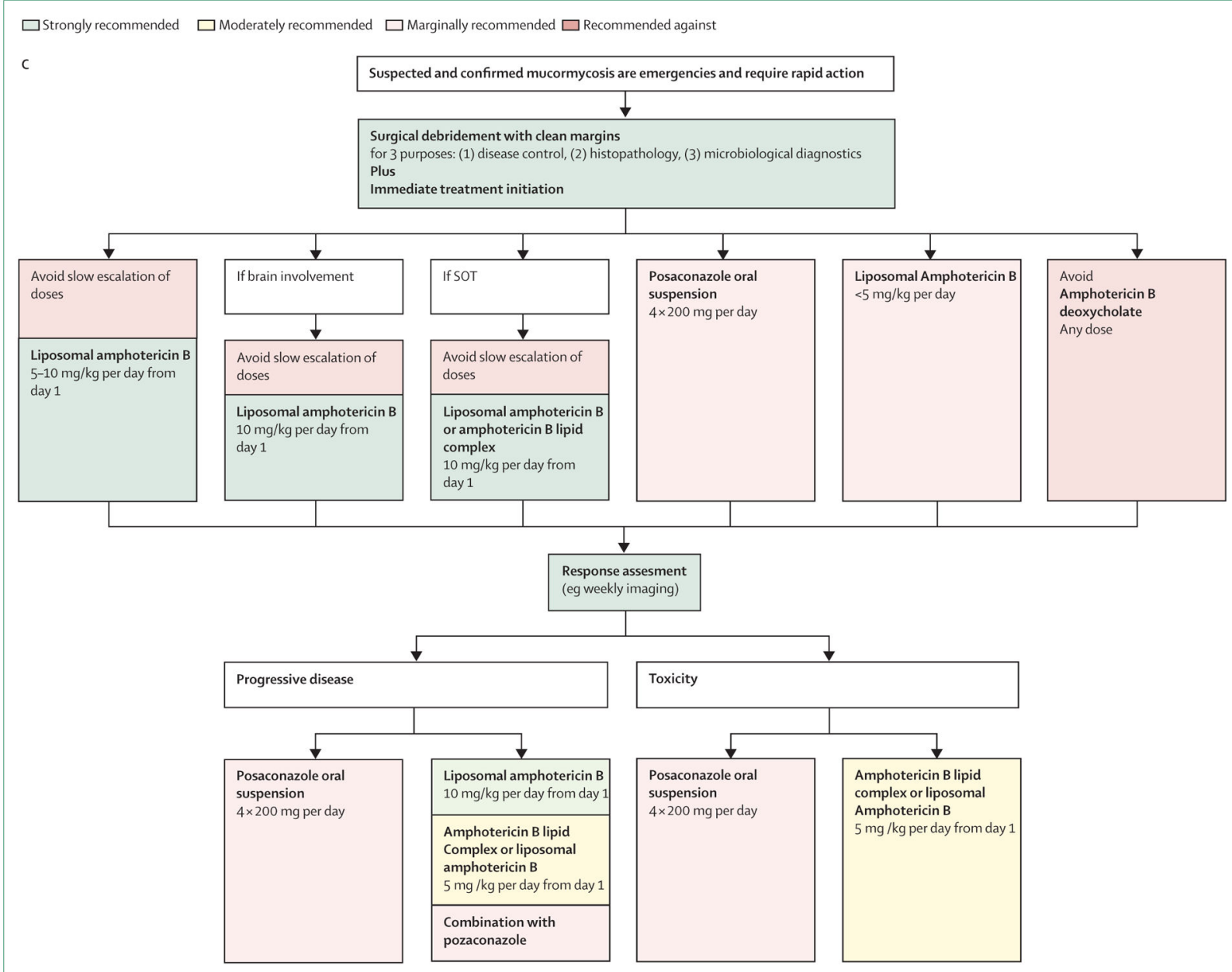

Figure 5: Optimal treatment pathways for mucormycosis in adults

Depending on the geographical location not all recommended treatments may have regulatory approval for use in clinical settings. (A) When all treatment modalities and antifungal drugs are available, (B) when amphotericin B lipid formulations are not available, and $(\mathrm{C})$ when isavuconazole and posaconazole IV and delayed release tablets are not available. IV=intravenous. $\mathrm{PO}=$ per os (taken orally). SOT=solid organ transplantation. $\mathrm{DR}=$ delayed release. 


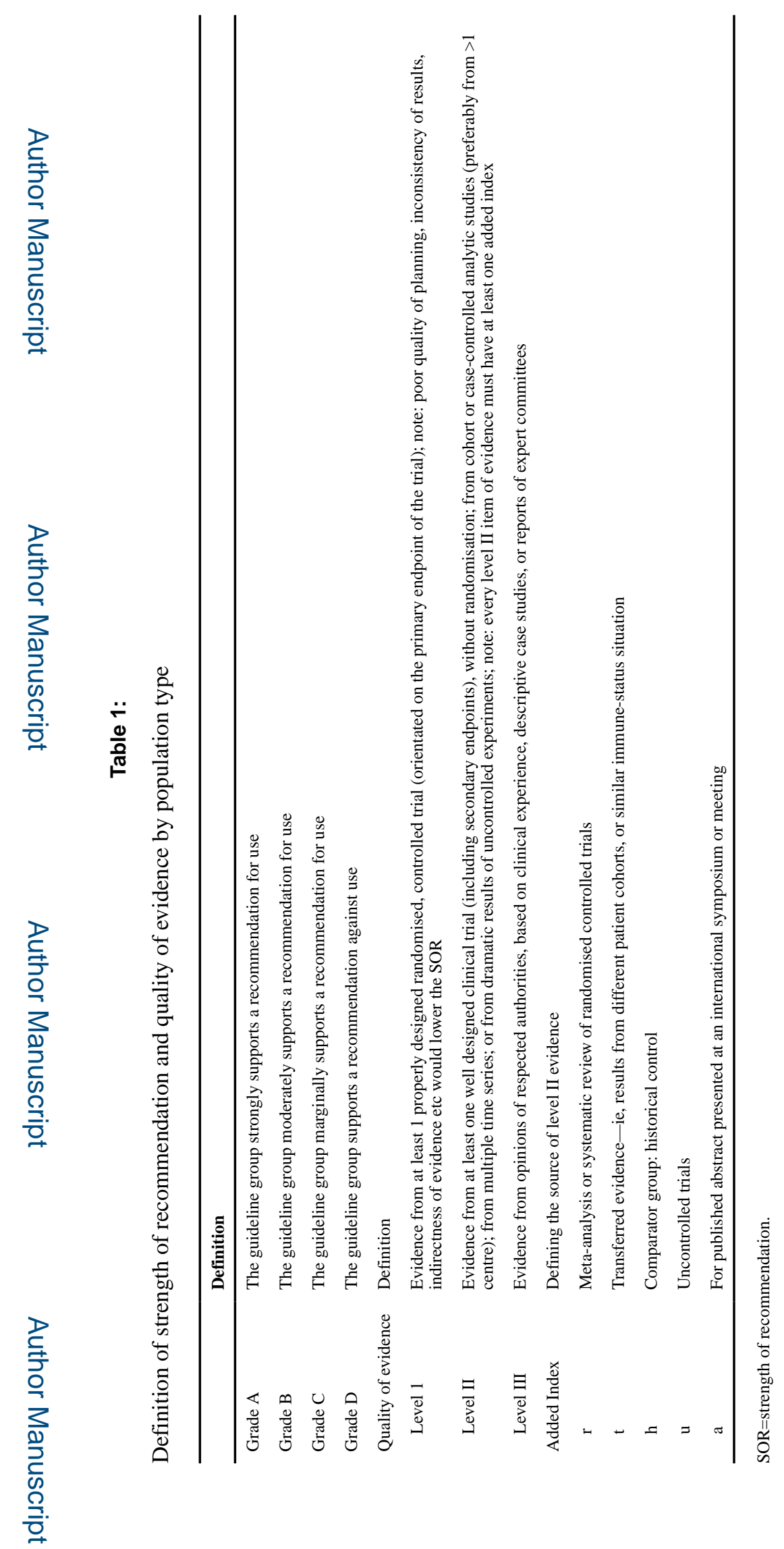

Lancet Infect Dis. Author manuscript; available in PMC 2021 November 01. 




Lancet Infect Dis. Author manuscript; available in PMC 2021 November 01. 